\title{
is Research Square \\ Identification and characterization of GAP50 binders with the goal to identify novel antimalarials
}

Dinkar Sahal ( $\nabla$ dsahal@gmail.com )

International Centre for Genetic Engineering and Biotechnology

Prakhar Agrawal

International Centre for Genetic Engineering and Biotechnology

Surekha Kumari

CSIR-Institute of Himalayan Bioresource Technology

Upendra Sharma

CSIR-Institute of Himalayan Bioresource Technology

\section{Research Article}

Keywords: Malaria, Plasmodium, GAP50, Merozoite, invasion, Bedaquiline, Brilacidin, Hayatinine, Curine

Posted Date: February 3rd, 2022

DOl: https://doi.org/10.21203/rs.3.rs-1272462/v1

License: @ (i) This work is licensed under a Creative Commons Attribution 4.0 International License. Read Full License 


\section{Abstract}

Malaria continues to be a killer disease even in the modern world. Indeed, vaccines and drugs have a lot to learn from the malaria parasite before they can be successful. Here, using a filter for glideosomal anchor protein PfGAP50, we have explored a plethora of small molecules to shortlist eight GAP50 binders with promising antiplasmodial activity $\left(\mathrm{IC}_{50}<3\right.$ $\mu \mathrm{M})$ that are also highly selective. Of these, Hayatinine, Curine, MMV689758 (Bedaquiline), MMV1634402 (Brilacidin), and MMV688271 with PfINDO IC $50 \leq 1 \mu \mathrm{M}$ were found to stall merozoite invasion by inhibiting IMC formation besides increasing oxidant levels in trophozoites. Bedaquiline pre-treated and washed healthy RBCs showed prophylactic ability to prevent intraerythrocytic development of malaria parasite. Synergistic activities with $\Sigma$ FIC values as low as 0.22 (Curine and Artemisinin) or 0.37 (Bedaquiline and Artemisinin) augur well for the development of drug combinations to combat malaria effectively. Interestingly, orally delivered Bedaquiline (50 mg/Kg b. wt.) showed substantial suppression of parasitemia in a mouse model of malaria.

\section{Significance Of The Work}

Our study offers a new set of drug-like molecules screened against the essential glideosomal protein GAP50. These asexual stage targeting molecules may have good prospects against other parasitic apicomplexans as well. Further, with good selectivity towards Plasmodium, these molecules can be starting points for future optimization towards the design of novel antimalarials.

\section{Introduction}

Notwithstanding intense efforts to discover drugs and vaccines and attempts to combat it through vector control, malaria continues to be a deadly curse in Africa, Asia, and South America. Current and past antimalarials such as quinoline and artemisinin derivatives, antifolates, and antibiotics targeted metabolic pathways in the asexual stage of Plasmodium ${ }^{1}$. With the emergence of artemisinin-resistant parasite strains and the inability of Artemisinin Combination Therapies (ACT) to clear them, there is a need to identify and aim antimalarials at novel targets with new mechanisms of action. In humans, the mosquito vector-borne malaria parasite traverses through different developmental stages, first in the liver and then in the blood. Of these, invasion is an essential process for parasite survival and proliferation within the immunologically safe and nutritionally rich confines of the host cell. This process has led to vaccine based approaches against several invasion related proteins including MSP- $1^{2}$ and $M S P 2^{3}, A M A 1^{4}, \mathrm{Rh} 5^{5}$, and EBA $175^{6}$. However, the limited efficacy of these vaccines and the complex life cycle of the malaria parasite with its ability to mutate proteins have been major hurdles in their successful development. Against this background, we selected the glideosomal complex which propels the process of fast invasion as a potential target for drug discovery. The proteins of this complex are involved in the proliferation of both sexual and asexual stages of Plasmodium and their disruption is known to curtail the parasite ${ }^{7-}$ 10. The glideosomal complex consists of glideosome associated proteins ${ }^{11-13} 40,45,50$, and 70 (GAP40 GAP45, GAP50, GAP70) along with GAPMs ${ }^{14,15}$, Myosin A (MyoA), and myosin A tail-interacting protein (MTIP) $)^{16}$. Amongst all these proteins, GAP50 which is highly conserved in Apicomplexans plays a pivotal role by acting first as a scaffolding protein and next by anchoring the glideosomal complex ${ }^{17}$ to the inner membrane ${ }^{11,18}$. Although GAP50 has been studied as a potential transmission-blocking vaccine candidate ${ }^{19}$, it has not till date been studied as a drug target. The $1.7 \AA$ resolution crystal structure of GAP50 by Bosch et. $\mathrm{al}^{20}$ has further paved the path for anti-malarial drug discovery by targeting this protein. Given the paucity of studies in this direction, here we have chosen to screen numerous small molecules of diverse chemical classes against PfGAP50. We believe that the promising molecules thus identified might become the starting points of development for future antimalarials having the potential to disrupt the delicate organization of the glideosomal complex. 
To achieve our goal, we screened diverse compounds coming from MMV (pathogen, and pandemic box) as also laboratory synthesized quinolines (Supplementary Table 1$)^{21}$ and some phytometabolites isolated in our laboratory (Supplementary Fig 1) 21,22 against PfGAP50. Successive compound screenings which started with initial permissive cutoffs used in diverse in silico and wet lab binding assays were followed by more stringent in vitro inner membrane complex disruption microscopic assays, in vitroP. falciparum culture based $\mathrm{IC}_{50}$, and mammalian cells-based selectivity cut-offs. Our successive screenings have led to the identification of potent antiplasmodial lead molecules endowed with high selectivity and low resistance indices that have multi-stage activities. The molecules thus identified can serve as starting points for the development of new antimalarials.

\section{Methods}

\section{Recombinant Expression and affinity purification of PfGAP50}

Pf3D7 genomic DNA was used to PCR amplify the PfGAP50 gene using PfGAP50 specific primers (5'TTTTCATATGAAATGTCAACTACGCTTTGCG-3'- FP) and (5'-TTTGGATCCTTAATCTTTATTTCCCATGGGTCC-3'$\mathrm{RP}$ ). The amplified product was cloned in $\mathrm{pET} 28 \mathrm{a}^{+}$vector (Supplementary Fig-6) which was transformed into Rosetta 2 pLyS strain with ligation of PCR product downstream of His tag sequence. Using $1 \%$ inoculum of the primary culture, secondary culture was initiated in TB broth supplemented with $\mathrm{CoSO}_{4}(2 \mu \mathrm{M}), \mathrm{Kanamycin}(50 \mu \mathrm{g} / \mathrm{ml})$, and Chloramphenicol $34 \mu \mathrm{g} / \mathrm{ml}^{20}$. Cells at $A_{600} 2.0$ were induced with isopropyl $\beta$-D thiogalactopyranoside $(0.5 \mathrm{mM})$ at $18^{\circ} \mathrm{C}$ for $16 \mathrm{hrs}$. Harvested cells were lysed by sonication in buffer A (50 mM Tris HCl, pH 8.3 supplemented with 10\% glycerol and $300 \mathrm{mM} \mathrm{NaCl})$. Cellular debris was removed by centrifugation $\left(13000 \mathrm{~g}, 45 \mathrm{~min}, 4^{\circ} \mathrm{C}\right)$ and the clear supernatant was loaded on to a preequilibrated Ni-NTA column. The column was washed using buffer A with 30 column volumes (CV) and the terminal elute was found to be protein-free as tested by Bradford assay. The bound protein was eluted using buffer $B$ (50 mM Tris- $\mathrm{HCl}, \mathrm{pH} 8.3,500 \mathrm{mM} \mathrm{NaCl}, 10 \%$ glycerol, $0.5 \mathrm{M}$ imidazole). The eluted proteins were subjected to hydrophobic interaction chromatography by loading them onto a $1 \mathrm{M}$ ammonium sulphate in $50 \mathrm{mM}$ Tris-HCl pH 8.3 (Buffer $\mathrm{C}$ ) preequilibrated phenyl sepharose column followed by washing with buffer $\mathrm{C}$ (30 CVs) and elution using decreasing gradient of ammonium sulphate. The purified protein was then dialyzed against the imidazole free buffer $\mathrm{B}$ and stored at $4^{\circ} \mathrm{C}$ (up to 2 months).

\section{In silico docking, molecular dynamics simulation and -dG of binding}

The PDB crystal structure of PfGAP50 (ID: 3TGH) was prepared for docking using the protein preparation wizard ${ }^{23}$ of $^{2}$ Schrödinger software (version 19-3). Ligand structures drawn using ChemSketch (version 2021.1.2) software were imported into Schrödinger software. Ligprep ${ }^{23}$ was used to prepare ligands for docking. Grid was generated to engulf the entire protein, and docking was carried out using the Glide module ${ }^{24}$. Docked poses were then taken for estimation of -dG of binding using the Prime MM-GBSA module ${ }^{25}$. Lead PfGAP50 binders (Bedaquiline, Hayatinine, Brilacidin, MMV688271, and Curine) that showed good promise also in $P$. falciparum culture-based study were taken for the molecular simulation study $^{26}$. Briefly, the protein-ligand complex was solvated using the TIP4PEW model in an orthorhombic box. $\mathrm{Na}^{+}$and $\mathrm{Cl}^{-}$ions were added to neutralize the system. OPLS3e force field was used to simulate for $100 \mathrm{~ns}$. In a quest to determine alternate targets of lead molecules, cross-docking was performed using in silico Schrödinger tool. Briefly, malaria parasite protein structures were taken from PDB, and a grid was generated around co-crystallized ligands after preparing the protein and ligand structures. Docking was done using glide module following which binding free energies of proteinligand complexes were calculated using Prime MM-GBSA tool.

\section{Compounds}


Pathogen and Pandemic box compounds dissolved in DMSO at $10 \mathrm{mM}$ were obtained from MMV. Azepino quinolines ${ }^{21}$ and molecules from Cissampelos pareira ${ }^{22}$ (Hayatinine, Curine and Magnocurarine) were from Dr. Upendra Sharma, IHBT, India. The sources of these drug-like molecules were: Bedaquiline (MMV689758) or HY-14881/CS-2921 (Med Chem Express), Mefloquine or M2319 and Bitertanol or 45349 (Sigma), Pentamidine or 20679 (Cayman chemicals), Suramin or 1874-250 (Bio vision), and MMV688771 or S14135SC (May bridge). Additionally, the MMV series of molecules 1634402 (Brilacidin), 1782353, 642550, and 688271 were procured from MMV.

\section{Screening of molecules using differential scanning fluorimetry}

Recombinantly expressed and highly purified PfGAP50 was used for in vitro small molecule binding using Differential Scanning Fluorimetry (DSF). Compounds were screened at $200 \mu \mathrm{M}$ using $10 \mu \mathrm{M}$ of protein. DSF experiment was set up as described by Huynh, K., \& Partch, C.L. ${ }^{27}$. $T_{m}$ was calculated using nonlinear regression model of Boltzmann Sigmoidal curve using the following equation

$$
\mathrm{Y}=\text { Bottom }+(\text { Top }- \text { Bottom }) /\left\{1+\exp \left(\operatorname{Tm}-\frac{\mathrm{X}}{\text { Slope }}\right)\right\}
$$

where Y: fluorescence emission in arbitrary units; $X$ : temperature; Bottom: baseline fluorescence at low temperature; Top: maximal fluorescence; Slope: the steepness of the curve; and $T_{m}$ : melting temperature of the protein. The binding of some small molecules may manifest as a decrease or increase in protein stability. Molecules that gave a $\Delta \mathrm{T}_{\mathrm{m}}>2.0^{\circ} \mathrm{C}$ over the solvent control were taken as potential hits.

\section{Binding affinity determination using surface plasmon resonance}

PfGAP50 $(50 \mu \mathrm{g} / \mathrm{ml})$ was immobilized on a CM5 chip in acetate buffer, pH 4.5 using EDC-NHS coupling. Small test molecules were diluted in 1x PBS supplemented with $5 \%$ DMSO with $0.005 \%$ Polysorbate 20 (running buffer) to yield solutions of varying concentrations (two-fold serial dilution from $50 \mu \mathrm{M}$ to $0.3125 \mu \mathrm{M}$ ) that were allowed to flow over the immobilized protein at a flow rate of $30 \mu \mathrm{l} / \mathrm{min}$. Contact and dissociation times of 60 and $120 \mathrm{sec}$, respectively were given for each cycle. Regeneration was carried out using $10 \mathrm{mM}$ glycine pH 3.0. Data obtained was fitted with a 1:1 binding model to get $\mathrm{K}_{\mathrm{a}}$ (association constant), $\mathrm{K}_{\mathrm{d}}$ (dissociation constant), and $\mathrm{KD}$ (equilibrium binding affinity constant).

\section{In vitro maintenance of $P$. falciparum cultures and assessment of antiplasmodial activity of test molecules}

Laboratory adapted Pf3D7 (MRA102), PfNDO (MRA819), and PfCam 3.1 ${ }^{\text {R539T }}$ (MRA1240) were procured from BEl resources and maintained in $\mathrm{O}^{\text {tve }}$ human RBCs collected from Rotary blood bank, New Delhi. Cultures at $4 \%$ haematocrit, $(\mathrm{H})$ were allowed to grow in complete RPMI 1640 medium at $37^{\circ} \mathrm{C}$ under reduced $\mathrm{O}_{2}$ (gas mixture $5 \% \mathrm{O}_{2}, 5 \% \mathrm{CO}_{2}$, and $90 \%$

$\mathrm{N}_{2}$ ) as described by Trager \& Jenson ${ }^{28}$. Antiplasmodial activities of test compounds were evaluated by fluorescencebased 96 -well format SYBR green I assay as described by Smilkstein et $\mathrm{al}^{29}$ using chloroquine $(4 \mu \mathrm{M})$ as zero growth positive control and $0.4 \%$ DMSO as $100 \%$ growth negative control.

\section{In vitro cell cytotoxicity assay against mammalian cell lines}


Human cell lines HUH-7 \& HEK293 were used to determine cytotoxic effects of test compounds by using MTT [3-(4,5dimethylthiazol-2-yl)2,5-diphenyltetrazolium bromide] assay for mammalian cell viability as described by Mosmann ${ }^{30}$. Cells were cultured in $10 \%$ fetal bovine serum supplemented DMEM (cDMEM). Briefly, trypsinized cells $\left(10^{4}\right.$ cells $/ 200 \mu \mathrm{L}$ cDMEM/well) were seeded in triplicate into 96-well flat-bottom tissue-culture plates. Following $16 \mathrm{~h}$ cell seeding in triplicate, $200 \mu \mathrm{L}$ of media was replaced with $96 \mu \mathrm{L}$ of fresh cDMEM and test molecule solutions $(4 \mu \mathrm{L})$ were added. Culture plates were incubated for $24 \mathrm{~h}$ in a humidified atmosphere at $37^{\circ} \mathrm{C}$ and $5 \% \mathrm{CO}_{2} .10 \%$ and $0.8 \% \mathrm{DMSO}(\mathrm{v} / \mathrm{v})$ were used as +ve (zero growth) and -ve (100\% growth) controls respectively. After $24 \mathrm{~h}$ treatment, $20 \mu \mathrm{L} \mathrm{MTT}(5 \mathrm{mg} / \mathrm{mL}$ in $1 \mathrm{x}$ PBS) solution was added to each well, and plates were incubated for four hours at $37^{\circ} \mathrm{C}$. Thereafter, plates were centrifuged (700 g, $10 \mathrm{~min}$ ), and supernatants were aspirated out using a multi pipette. This was followed by the addition of $200 \mu \mathrm{L}$ of DMSO and incubation of the plate at $37^{\circ} \mathrm{C}$ for $10 \mathrm{~min}$. The amount of formazan (a measure of cell growth) formed was assessed by measuring O.D. at $570 \mathrm{~nm}$.

\section{Stage-specific inhibition}

PfINDO cultures at 0 to $6 \mathrm{~h}$ post-invasion (p.i) (rings), 18 to $22 \mathrm{~h} \mathrm{p.i} \mathrm{(trophozoites),} 30$ to $34 \mathrm{~h} \mathrm{p.i} \mathrm{(early} \mathrm{schizonts),} \mathrm{and} 40$ to $44 \mathrm{~h}$ p.i (late schizonts) were incubated with varying concentrations of test molecules for a period of $12 \mathrm{~h}$ followed by test molecule removal by centrifugal media washes and allowing cultures to grow for $2^{\text {nd }}$ cycle ( $\left.48 \mathrm{~h}\right)$ in test molecule free media. $\mathrm{IC}_{50}$ (concentration of test molecule at $50 \%$ growth) was obtained by plotting growth curves with untreated, and Chloroquine treated cultures acting as $100 \%$ and $0 \%$ growth controls, respectively.

\section{In vitro test molecule retention by uninfected RBCs}

Uninfected RBCs $\{2 \%$ Hematocrit $(\mathrm{H})\}$ were incubated with each test molecule at the respective $10 x \mathrm{IC}_{50}(P f \mathrm{NDO})$ for $72 \mathrm{~h}$, followed by three centrifugal washes with $1 \times$ PBS. MACS enriched schizonts ${ }^{31}\{100 \%$ Parasitemia $(P)\}$ were added to the washed RBCs at final $1 \% \mathrm{P} \& 2 \% \mathrm{H}$. The plate was then incubated at $37^{\circ} \mathrm{C}$ for $96 \mathrm{~h}$ with media refreshment every $24 \mathrm{~h}$. Percentage growth was evaluated by SYBR green I lysis method ${ }^{29}$, and the cell cycle stage progressions were monitored microscopically using Giemsa-stained smears.

\section{Oxidant level measurement using CM-H2DCFDA dye}

Oxidant level measurement was carried out using the protocol provided by the manufacturer (Invitrogen). This technique employs the cell-permeant 2',7'-dichlorodihydrofluorescein diacetate $\left(\mathrm{H}_{2} \mathrm{DCFDA}\right)$, which in its native ester form is reduced and non-fluorescent. However, inside cells, it is trapped and undergoes esterase catalyzed de-esterification followed by oxidation to the highly fluorescent 2',7'-dichlorofluorescein (DCF). Briefly, PfINDO trophozoites (24 to $28 \mathrm{~h}$ p.i) culture at $2 \%$ $\mathrm{P}$ and $2 \% \mathrm{H}$ was incubated with $\mathrm{CM}-\mathrm{H}_{2}$ DCFDA dye $(5 \mu \mathrm{M}, 30 \mathrm{~min})$ followed by washing cells with $1 \times$ PBS and treatment with test molecules at $2 \times I_{50}$ (LRàET) for $8 \mathrm{~h}$ and $12 \mathrm{~h}$ respectively. Post-treatment, fluorescence was measured at 530 nm using Spectra Max multi-mode plate reader machine. $\mathrm{H}_{2} \mathrm{O}_{2}(100 \mu \mathrm{M})$ treated parasitized RBC (PRBC) and 0.4\% DMSO $(\mathrm{v} / \mathrm{v})$ treated uninfected RBC (URBC) were taken as +ve and -ve controls respectively.

\section{Egress/invasion inhibition assay}

This assay employed a late schizont to early ring (LS à ER) readout where late schizonts were treated with test molecule for $8 \mathrm{~h}$ followed by culture in test molecule free medium for a time sufficient to give rings in untreated control culture. For this, PfINDO (42 to $45 \mathrm{~h} \mathrm{p.i)} \mathrm{culture} \mathrm{was} \mathrm{diluted} \mathrm{to} 1 \% \mathrm{P}$ at $2 \% \mathrm{H}$ in cRPMI and treated with test molecules at $2 \mathrm{x} I \mathrm{C}_{50}$ for 8 
h. This was followed by removal of test molecules by three centrifugal washes with 1x PBS and incubation of the washed cells in fresh cRPMI for $48 \mathrm{~h}$. \% $\mathrm{P}$ was calculated at the end of the $2^{\text {nd }}$ cycle using SYBR Green staining and counting $10^{5}$ cells via FACS.

\section{Evaluation of GAP50 binder antiplasmodial molecules as disruptors of inner membrane complex formation and invasion}

Saini et al ${ }^{32}$ have described in malaria parasite the presence of yet another multiprotein complex called Phil1 in close proximity of the glideosomal complex. Interestingly both these complexes present in the space between the plasma membrane and inner membrane have GAP50 as one of the constituents and both complexes appear to play a crucial role in the process of merozoite invasion. In this assay, we have used Phil1 and GAP50 antibodies to track the development of Schizont's inner membrane complex (IMC) in the presence vs absence of the small test molecules that bind GAP50. Early schizonts (30 to $34 \mathrm{~h} \mathrm{p.i)} \mathrm{were} \mathrm{treated} \mathrm{with} \mathrm{test} \mathrm{compounds} \mathrm{for} 12 \mathrm{~h}$, followed by indirect immunofluorescence assay (IFA) to assess IMC development. For this, cells were rinsed once with 1x PBS and fixed using a solution containing paraformaldehyde (4\% v/v) and glutaraldehyde $(0.0075 \% \mathrm{v} / \mathrm{v})$ in PBS for $30 \mathrm{~min}$. The fixed cells were treated with Triton $\mathrm{X}-100(0.1 \% \mathrm{v} / \mathrm{v})$ in $1 \mathrm{x}$ PBS (twice, $15 \mathrm{~min}$ each) and the so permeabilized cells were blocked using BSA (4\% w/v in $1 \mathrm{x}$ PBS). Parasites were then incubated with $1^{\circ} \mathrm{Ab}$ at $1: 50$ dilution overnight at $4^{\circ} \mathrm{C}$, followed by washing and incubation with $2^{\circ} \mathrm{Ab}$ (Alexa conjugated anti-rabbit antibody 488 , Invitrogen) at 1:500 dilution for $3 \mathrm{~h}$ at RT. In the end, DAPI (10 $\left.\mu \mathrm{g} / \mathrm{mL}\right)$ was used to stain the nucleus (10 min at RT). Samples were imaged using Nikon A1-R confocal microscope. Similarly, segmented schizont cultures ( 42 to 46 h. p.i) were treated with test molecules for $8 \mathrm{~h}$ and evaluated via IFA for their ability to egress and the resulting merozoites to invade healthy red blood cells leading to the formation of rings.

\section{In vitro potency of the combinations of lead anti-plasmodial molecules}

To determine the effect of combining drugs on potency, different drug combinations were made to determine $\mathrm{IC}_{50}$ of combinations against synchronous ring stage ( 6 to $12 \mathrm{~h} \mathrm{p.i,} \mathrm{at} 1 \% \mathrm{P}$ and $2 \% \mathrm{H}$ ) of $P$. falciparum (MRA1240) in culture. $8 \mathrm{x}$ $\mathrm{IC}_{50}$ of each test molecule in $10 \%$ DMSO / 1x PBS was taken as stock (A) and mixed with $8 \mathrm{x} \mathrm{IC}_{50}$ of standard antimalarials $(B)$ in four different molar ratios (4:1, 3:2, 2:3, and 1:4). Each ratio sample was further serially two-fold diluted in 10\% DMSO/ 1x PBS. Four microliters of each dilution were mixed with $96 \mu$ l of parasite culture $(1 \% \mathrm{P}, 2 \% \mathrm{H})$. Thus, each experimental well contained a total volume of $100 \mu \mathrm{l}$ with or without test molecules. Control ( $0.4 \%$ DMSO $(\mathrm{v} / \mathrm{v}))$ that is nontoxic to the parasite was used as -ve control (100\% growth) whilst Chloroquine $(4 \mu \mathrm{M})$ was used as $+\mathrm{ve}$ control $\left(0 \%\right.$ growth). The plates were incubated $\left(37^{\circ} \mathrm{C}, 72 \mathrm{~h}\right)$ followed by an estimation of parasite proliferation using the SYBR Green I lysis method ${ }^{29}$. Data analysis was done as described by Thapar et $\mathrm{al}^{33}$. The sum of Fractional inhibitory concentrations $\left(\sum \mathrm{FIC}\right)$ was calculated as $\mathrm{FIC}_{A}+\mathrm{FIC}_{\mathrm{B}}$, where $\mathrm{FICs}$ are: $\mathrm{FIC}_{A}=\mathrm{IC}_{50}$ of $\mathrm{A}$ in combination/IC $\mathrm{I}_{50}$ of $A$ when alone; $\mathrm{FIC}_{\mathrm{B}}=\mathrm{IC}_{50}$ of $\mathrm{B}$ in combination/ $\mathrm{IC}_{50}$ of $\mathrm{B}$ alone. The sum of $\mathrm{FICs} \sum \mathrm{FIC}=\mathrm{FIC}_{\mathrm{A}}+\mathrm{FIC}_{\mathrm{B}}$, was used to classify interactions $^{34}$ as strongly synergistic $\left(\sum \mathrm{FIC} \leq 0.5\right)$, weakly synergistic $\left(\left(\sum\right.\right.$ FIC $\left.0.5-1\right)$, additive $\left(\sum\right.$ FIC $\left.1-2.0\right)$ or antagonistic $\left(\sum \mathrm{FIC}>2.0\right)$.

\section{In vivo acute toxicity study}

In vivo acute toxicity was done as per OECD 423 guideline ${ }^{35}$. Briefly, mice fasted for $4 \mathrm{~h}$ before oral dosing of test molecules. After dosing, mice were kept under observation for the next 45 min for any acute toxicity symptoms followed by resumption of their feed and a daily check over 16 days for any long-term toxicity symptoms. 


\section{In vivo antimalarial study}

In vivo antimalarial study was carried out as per ARRIVE guidelines 2.0 with prior permission from ICGEB animal ethical committee (ICGEB/IAEC/30012021/MPB-8). Briefly, $10^{5}$ P. berghei ANKA infected RBCs were injected into mice (6 to 8 weeks old, average weight $20 \pm 2 \mathrm{gm}$ ) and grouped randomly with seven mice/group. After $24 \mathrm{~h}$ of infection, test molecules were orally administered in vehicle solution (2\% (Hydroxypropyl) methylcellulose with 2\% Tween 80 in Normal saline) for four consecutive days followed by daily monitor of \% P, body weight, and surface temperature day 5 to day $30^{36}$. Chloroquine (50 mg/kg b. wt.) was taken as + ve control.

\section{Results}

\section{Screening of 951 compounds}

A total of 951 different compounds from diverse chemical libraries [pathogen box (400), pandemic box (400), Azepino quinolines and quinolines with $\beta$ benzomorphan framework ${ }^{21}(140)$, and secondary metabolites purified from $C$. pareira ${ }^{22}$ (11)] were screened (Fig. 1a) for (a) in silico interactions with PfGAP50 via Schrödinger drug discovery suite (version 20193 ), and (b) ability to influence the melting temperature of GAP50 using differential scanning fluorimetry (DSF). The results of these two screens were then validated using Surface Plasmon Resonance (SPR) with recombinantly expressed and affinity-purified PfGAP50 (Supplementary Fig. 2 and 3) immobilized on the CM5 chip. Permissive cut-off values for in silico screening were kept at $<-20 \mathrm{kcal} / \mathrm{mol}$ (MMGBSA dG of binding) while, a $\delta \mathrm{T}_{\mathrm{m}}$ cut-off was kept at $\pm 2{ }^{\circ} \mathrm{C}$ was chosen for DSF based screening. Among all compounds taken for in silico screening, there were few with promising docking scores [> - 5] and MMGBSA dG binding [>- $40 \mathrm{kcal} / \mathrm{mol}]$ (Supplementary Fig. 4). Likewise, in the case of DSF few compounds showed $\mathrm{T}_{\mathrm{m}}$ shifts up to $+32^{\circ} \mathrm{C}$ and $-20^{\circ} \mathrm{C}$ (Supplementary Figs. 5-7). The independent use of both in silico docking and DSF $\left(\delta T_{m}\right)$, helped in the selection of 345 of the 951 compounds (Fig. 1a).

Since both in silico docking and DSF can occasionally give false positives ${ }^{37-39}$, we used Surface Plasmon Resonance $(\mathrm{SPR})^{40}$ to validate the binding of the shortlisted 345 molecules to GAP50 immobilized on the CM5 chip. Compounds at definite concentration were passed over the immobilized protein and interactions-based sensorgrams were obtained. Initial screening of 345 different molecules at $50 \mu \mathrm{M}$ concentration each, allowed the selection of 266 molecules that exhibited 1:1 binding with GAP50. Further, these selected 266 molecules were allowed to interact with GAP50 using SPR in a concentration-dependent manner for equilibrium binding affinity (KD) determination. Based on KD, 84 compounds were identified as true GAP50 binders (Supplementary file 2).

\section{In silico stabilities of complexes of PfGAP50 with Bedaquiline, Hayatinine, MMV688271, Curine, and Brilacidin}

Studying the finer nuances of the mode of binding of small molecule ligands to the target proteins of interest can facilitate the development of structure-based novel therapeutics. Towards this goal, of the eight promising molecules (Fig. 1b) the five including Bedaquiline, Brilacidin, Curine, Hayatinine, and MMV688271 which were found to be the most promising in most screens were shortlisted for MD simulation to assess the dynamic stability of their intermolecular interactions with amino acid residues constituting the respective binding pockets in PfGAP50. A brief description of molecule specific interactions is given below:

Bedaquiline was found to be interacting through hydrophobic interactions (W35, 169, H256, M278), hydrogen bonding (G65), and a water bridge (N221), (Supplementary Fig. 8 and 9). These interactions were found to be maintained over 30\% of 100 ns simulation time and appeared to be helping in stabilizing the binding of Bedaquiline with GAP50, resulting in 
$-36.9 \mathrm{kcal} / \mathrm{mol}$ binding energy (Supplementary Table 2). The sensorgram profile obtained using one-on-one interaction with GAP50 (Supplementary Fig. 9b) indicated a binding affinity (KD) of $9.27 \mu \mathrm{M}$.

The binding of Brilacidin with GAP50 (Supplementary Fig. 10 and 11) was found to be majorly driven by water bridges mediated via the side chains and the backbone of N127, E129, N148, D201, I322, N349, E351, and L352 which were further strengthened by Hydrogen bond interactions involving E129, E351, and L352. Amongst these interactions, the ones with E129 and E351 were maintained for $>50 \%$ of 100 ns simulation time (Supplementary Fig. 10d). The presence of as many as sixteen water bridges between Brilacidin and GAP50 may have contributed to the most promising MMGBSA dG binding of $-64.82 \mathrm{kcal} / \mathrm{mol}$ (Supplementary Table 3), with KD $2.81 \mu \mathrm{M}$ (Supplementary Fig. 11b).

Interactions of MMV688271 (Supplementary Fig. 12 and 13) with GAP50 were found to be stabilized through Hydrogen bonds (E123, H152, F344, L347, P348), water bridges (E123, H152, F344, L347), and hydrophobic interactions (H152, F344, L347, V350). Varied interactions of MMV688271 with GAP50 might be the reason for the observance of low dG binding of $-41.86 \mathrm{kcal} / \mathrm{mol}$ with in vitro $\mathrm{KD}$ of $20 \mu \mathrm{M}$.

It was interesting to observe that the structurally close Curine and Hayatinine, bind to GAP50, but each bind to its unique site (Fig. 2). Further, SPR determined KD of Curine was nearly three times higher than that of Hayatinine, suggesting Hayatinine's interaction with GAP50 is stronger than is the case with Curine (Supplementary Fig. 14). Hayatinine was predicted to interact with $\mathrm{G} 119, \mathrm{Q} 120, \mathrm{M} 146, \mathrm{P} 147$, and H152 via water bridge and E133 via hydrogen bond

(Supplementary Fig. 15 and 16). These bonds that were found to persist for $>30 \%$ of simulation time, might be preventing Hayatinine from moving out of its surface binding site (Supplementary Fig. 15b). Residues interacting with Curine (Supplementary Fig. 15 and 17) via hydrogen bonds, hydrophobic interactions, and water bridges were Y96, L134, D135, D137, A138, V350, and E351.

\section{In vitro antiplasmodial potency and mammalian cell cytotoxicity}

Our next step for further shortlisting was screening all 84 molecules for their antiplasmodial $\mathrm{IC}_{50} \mathrm{~S}_{\text {against different strains }}$ of the malaria parasite (chloroquine-sensitive Pf3D7, chloroquine-resistant PfINDO, and artemisinin-resistant PfCam 3.1 ${ }^{\text {R539T }}$ strains) and Selectivity indices (SI) (Supplementary file 2). It is noteworthy that among the shortlisted molecules (Table 1), Bedaquiline, Brilacidin, MMV688271 MMV642550, and Hayatinine showed $I_{50 s} \leq 1.5 \mu M$ against all the three strains of Plasmodium. USINB4-124-8 and Hayatinine were found to be more active against PfCam 3.1 ${ }^{\text {R539T }}$ (IC 50 6.7 nM and $59 \mathrm{nM}$, respectively) than against PfINDO strain $\left(\mathrm{IC}_{50} 2.42 \mu \mathrm{M}\right.$ and $0.41 \mu \mathrm{M}$, respectively). On the other hand, MMV1782353 and Curine, which showed RIs $<1$ (RI INDO/3D7 0.64 and 0.34 , respectively), exhibited $\mathrm{RI}>1$ against $P f C a m$ $3.1^{\mathrm{R} 539 \mathrm{~T}}\left(\mathrm{RI}_{1240 / 3 \mathrm{D} 7} 21.25\right.$ and 1.91, respectively).

Table-1

In vitro anti-plasmodial IC $\mathrm{I}_{50}$, Mammalian cell $\mathrm{CC}_{50}$, Resistance Index (RI) and Selectivity index (SI) of top eight PfGAP50 binder 


\begin{tabular}{|c|c|c|c|c|c|c|c|c|c|c|}
\hline \multirow[t]{2}{*}{ S.No. } & \multirow[t]{2}{*}{ Test molecule } & \multicolumn{3}{|c|}{$\mathrm{IC}_{50}(\mu \mathrm{M})$ against $P f$ strains } & \multicolumn{2}{|c|}{$\begin{array}{l}\text { Resistance } \\
\text { index* }\end{array}$} & \multicolumn{2}{|c|}{$\mathrm{CC}_{50}(\mu \mathrm{M})$} & \multicolumn{2}{|c|}{$\begin{array}{l}\text { Selectivity } \\
\text { index }{ }^{\star \star}\end{array}$} \\
\hline & & 3D7 & INDO & Cam3.1 ${ }^{\text {R539T }}$ & A & B & HEK293 & ${ }_{7}^{\mathrm{HUH}}$ & A & B \\
\hline \multirow[t]{2}{*}{1.} & \multirow[t]{2}{*}{ Hayatinine } & $0.5 \pm$ & \multirow{2}{*}{$\begin{array}{l}0.41 \pm \\
0.0059\end{array}$} & $0.059 \pm$ & \multirow[t]{2}{*}{0.82} & \multirow[t]{2}{*}{0.16} & \multirow{2}{*}{$\begin{array}{l}37.3 \pm \\
9.42\end{array}$} & \multirow{2}{*}{$\begin{array}{l}42.71 \\
\pm .22\end{array}$} & \multirow[t]{2}{*}{90.84} & \multirow[t]{2}{*}{104.00} \\
\hline & & 0.014 & & 0.0013 & & & & & & \\
\hline 2. & USINB4-124-8 & $\begin{array}{l}0.27 \\
\pm \\
0.013\end{array}$ & $\begin{array}{l}2.42 \pm \\
0.26\end{array}$ & $\begin{array}{l}0.0067 \pm \\
0.00037\end{array}$ & 8.96 & 0.02 & $>400$ & $>400$ & $>>$ & $\begin{array}{l}> \\
165.28\end{array}$ \\
\hline \multirow[t]{2}{*}{3.} & \multirow[t]{2}{*}{ Bedaquiline } & \multirow{2}{*}{$\begin{array}{l}1.22 \\
\pm \\
0.117\end{array}$} & \multirow{2}{*}{$\begin{array}{l}1.09 \pm \\
0.03\end{array}$} & $0.72 \pm$ & \multirow[t]{2}{*}{0.89} & \multirow[t]{2}{*}{0.59} & \multirow[t]{2}{*}{$>400$} & \multirow[t]{2}{*}{$>400$} & \multirow[t]{2}{*}{366.97} & \multirow[t]{2}{*}{366.97} \\
\hline & & & & 0.059 & & & & & & \\
\hline \multirow[t]{2}{*}{4.} & \multirow[t]{2}{*}{ MMV1782353 } & \multirow{2}{*}{$\begin{array}{l}0.63 \\
\pm\end{array}$} & \multirow{2}{*}{$\begin{array}{l}0.49 \pm \\
0.03\end{array}$} & $13.39 \pm$ & \multirow[t]{2}{*}{0.64} & \multirow[t]{2}{*}{21.25} & \multirow[t]{2}{*}{$>200$} & \multirow[t]{2}{*}{$>200$} & \multirow[t]{2}{*}{500.00} & \multirow[t]{2}{*}{500.00} \\
\hline & & & & 2.70 & & & & & & \\
\hline 5. & MMV642550 & 0.39 & $1.2 \pm$ & $1.49 \pm$ & 3.076 & 3.82 & $>200$ & $>200$ & 166.67 & 166.67 \\
\hline & & 0.026 & & 0.06 & & & & & & \\
\hline 6. & Brilacidin & 0.45 & $0.67 \pm$ & $0.865 \pm$ & 1.48 & 1.92 & $>200$ & $>200$ & 298.51 & 298.51 \\
\hline & & 0.024 & & 0.042 & & & & & & \\
\hline 7. & MMV688271 & 0.33 & $0.25 \pm$ & $0.337 \pm$ & 0.75 & 1.02 & $119.1 \pm$ & 29.65 & 478.31 & 119.08 \\
\hline & & 0.045 & & 0.034 & & & & 3.76 & & \\
\hline 8. & Curine & 1.46 & $0.51 \pm$ & $2.8 \pm$ & 0.34 & 1.91 & $104.1 \pm$ & 62.77 & 204.1 & 123.07 \\
\hline & & 0.10 & & 0.11 & & & & 6.60 & & \\
\hline
\end{tabular}

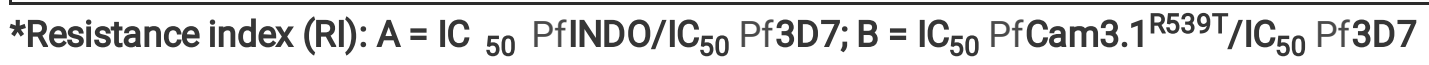

**Selectivity index (SI): A = CC ${ }_{50}$ HEK293/IC $C_{50}$ PfINDO; B $=\mathrm{CC}_{50}$ PfHUH7/IC ${ }_{50}$ PfINDO

\section{Inhibition of asexual stages of P. falciparum}

In its replicative phase, the malaria parasite traverses through diverse cell cycle stages like the ring (R), trophozoite $(T)$, and the Schizont (S). These three stages have morphologically identifiable sub-stages like early (E), and late (L). During these transitions, there are distinct changes in chromatin remodeling, transcriptome, and proteome of the malaria parasite, making some targets fade away and some new targets emerge $\mathrm{e}^{41}$. Hence it is not surprising to expect that $\mathrm{IC}_{50 \mathrm{~s}}$ determined against different stages of the malaria parasite can be quite different. In a bid to explore the differential vulnerability of cell cycle stages of the malaria parasite to our lead antiplasmodial molecules, we subjected different stages of the parasite to each lead molecule at different concentrations. As shown (Fig-3a), there were marked differences in the observed $\mathrm{IC}_{50 \mathrm{~s}}$ against different stages. Taking ER to LR, ET to LT, ES to LS, and LS to ER stages into consideration, USINB4-124-8 showed a much higher $\mathrm{IC}_{50}(\mu \mathrm{M})$ (38.12) against trophozoites and schizonts (54.32) than against rings (7.2). In contrast, MMV1782353 and MMV642550 showed good activity $\left(\mathrm{IC}_{50}<5 \mu \mathrm{M}\right)$ against early and late schizonts while showing less potency $\left(\mathrm{IC}_{50}>8 \mu \mathrm{M}\right)$ against rings (Fig-3a). It is noteworthy that despite great structural resemblance 
(Fig-1b), Hayatinine (608.7 Da) showed a marked preference to prevent LS to ER transition whereas the preference for Curine (594 Da) was ES to LS along with ET to LT transitions.

\section{Monitoring growth of malaria parasite in healthy RBCs "pre-treated" with test molecules}

Test molecules retained by RBCs can prevent the growth and maturation of the parasite. However, entrapment of test molecules by healthy RBCs is hitherto not a very well explored prophylactic strategy. In this experiment, we have pretreated healthy RBCs with $10 X \mathrm{IC}_{50}$ of each test molecule and used the washed RBCs for invasion by merozoites. Our results (Fig-3b) indicated that while RBCs pre-treated with Curine $(12.75 \mu \mathrm{M})$, Hayatinine $(10.25 \mu \mathrm{M}), \mathrm{MMV} 1782353$ (10 $\mu \mathrm{M})$, and USINB4-124-8 $(60.5 \mu \mathrm{M})$ showed $100 \%$ growth akin to control (0.4\% DMSO), the corresponding RBCs pre-treated with MMV642550 $(30 \mu \mathrm{M})$, Brilacidin $(16.75 \mu \mathrm{M})$, and MMV688271 $(2.49 \mu \mathrm{M})$ showed only $50 \%$ growth. Interestingly RBCs pre-treated with Bedaquiline $(27.25 \mu \mathrm{M})$, showed necrotic trophozoites with < $5 \%$ growth. It appears that Curine, Hayatinine, MMV1782353, and USINB4-124-8 are either not taken up or easily washed off from healthy RBCs. On the other hand, MMV642550, Brilacidin, and MMV688271 appear to be retained partially, which causes partial retardation in parasite growth. In a prophylactic role, Bedaquiline appeared to be the best in being retained at a concentration sufficient to kill the parasite (Fig-3b).

\section{Effect of test molecules on the creation of prooxidant milieu in the malaria parasite}

Cells work best at optimum Redox conditions created by homeostasis mediated by the combined actions of pro and antioxidant mechanisms present in every cell. Any imbalance in this homeostasis is lethal for the cell ${ }^{42}$. Given the robust heme detoxification mechanism that converts the prooxidant toxic heme to hemozoin along with Thioredoxin and Glutathione dependent antioxidant systems in the malaria parasite's metabolically active trophozoite stage $\mathrm{e}^{43}$, the fact that GAP50 binders showed preferential activity against trophozoites, made us examine if these test molecules influenced the redox milieu of the malaria parasite. When Trophozoites, pre-treated with redox sensitive H2DFCDA were treated with $2 x$ $\mathrm{IC}_{50}[\mathrm{ET} \diamond \mathrm{LT}]$ of lead molecules such as Bedaquiline and MMV688271, the dye fluorescence was found to be significantly increased wrt control, indicating increased oxidants in the parasite (Fig. 3c). Although the parasite is adept at regulating its redox status via diverse mechanisms, the skewed prooxidant status stimulated by the small molecules could overwhelm the parasite's redox homeostasis mechanisms and assist in killing the parasite.

\section{Effect of lead molecules on the rupture of schizonts and invasion by merozoites}

Since the invasion of merozoites is a crucial step preceding the exponential rise in \% parasitemia, molecules with $\mathrm{IC}_{50}<10$ $\mu \mathrm{M}$ against schizonts (Fig. 3a) were studied to examine (a) inhibition of egress of merozoites from schizonts and (b) merozoite invasion into healthy RBCs. Analysis of microscopic images indicated that in presence of MMV molecules 1782353 and 642550 , schizont rupture was stalled but once the test molecules were removed by centrifugal washings, schizonts were found to rupture and release merozoites. However, the released merozoites were unable to invade, leading to a sharp decrease in \% P akin to heparin, a known inhibitor of invasion ${ }^{44}$ (Fig-4a). In the case of Hayatinine, $8 \mathrm{~h}$ treatment of schizonts led to inhibition of egress with microscopic images showing many schizonts and just a few merozoites stuck to the RBC membrane. Curine allowed schizont egress, but the level of invasion was significantly reduced, suggesting that the treatment rendered the merozoites to be non-invasive. With no egress and no 
invasion, both Bedaquiline and MMV688271 showed schizontocidal activity on mature about to rupture schizonts (Fig4a). The five hit molecules with invasion inhibition comparable to control heparin were further confirmed for their invasion inhibitory activity by confocal microscopy (Fig-4b).

\section{IMC formation inhibition using Phil1 and GAP50 as a marker}

Since our target-based drug discovery was based on screening of small molecules against PfGAP50 and since GAP50 is a protein involved in the formation of IMC during schizogony ${ }^{13}$ and anchors several key proteins involved in invasion ${ }^{15}$, we checked whether our lead GAP50 binders $\left(\mathrm{IC}_{50}\right.$ against schizonts $\left.<10 \mu \mathrm{M}\right)$ at their sublethal concentrations could perturb IMC formation. Recent publications ${ }^{32,45}$ have shown colocalization of GAP50 complex with Phil1 complex. Indeed both these complexes seem to work in concert to facilitate the process of invasion ${ }^{32,45}$. Hence, we wanted to examine if the schizont targeting molecules identified by us may be disturbing the delicate interaction of these two complexes which gives proper organization to the IMC. With the availability of antibodies against both GAP50 and Phil1, co-localization of Phil1-GAP50 in control vs test molecule treated schizonts were studied. As shown (Fig-5), 0.4\% DMSO treated control schizonts which displayed proper development of schizonts with perfect co-localization of GAP50 with Phil1 showed a correlation coefficient P-value of 0.824. Similar colocalizations were seen also in cases of MMV688271 (P 0.886$)$ and Curine (P 0.888). In contrast, Hayatinine (P 0.617), Bedaquiline ( 0.641$)$, and Brilacidin ( 0.613 ) showed perturbations in IMC formation.

\section{In vitro effects of the combination of lead molecules with antimalarial drugs on ART resistant P. falciparum}

Drug combinations help in the assessment of synergistic, additive, or antagonistic activities. This, in turn, helps in the selection of combinations that retard the development of resistance, reduce toxicity, and increase the efficacy of the drugs used. Herein, we studied the potencies of molecules with $\mathrm{IC}_{50} P f C a m 3.1^{\mathrm{R} 539 \mathrm{~T}}<10 \mu \mathrm{M}$ viz. Hayatinine, Bedaquiline, MMV688271, MMV642550, Curine, USINB4-124-8, and Brilacidin in combination with standard antimalarial drugs Mefloquine, Pyrimethamine, and ART. As shown (Supplementary Table 3), we observed several instances of different kinds of drug interactions ranging from strong synergy to additivity to strong antagonism. When the $\sum$ FIC values were averaged over varying ratios of drug combinations (Fig-6), the combinations of Hayatinine and Curine with Artemisinin turned out to be synergistic (average $\sum \mathrm{FIC} \approx 0.5$ ) and additive (average $\sum \mathrm{FIC} \approx 1$ ) with $\mathrm{PYR}$ and MFQ. Likewise, the average $\sum$ FIC values for Bedaquiline, Brilacidin, MMV688271, and MMV642550 in combination with PYR, MFQ, and ART were additive while these values for USINB4-124-8 were additive with PYR and ART and antagonistic with MFQ.

\section{Putative antiplasmodial targets of Bedaquiline, Hayatinine, Brilacidin, MMV688271, and Curine}

The sub micromolar antiplasmodial $\mathrm{IC}_{50}$ of some of the compounds together with $\mu \mathrm{M} \mathrm{KD}$ against PfGAP50, led us to surmise that the malaria parasite proteome could have some more targets in addition to PfGAP50 for them. Hence lead invasion inhibitory molecules from each library (Bedaquiline and MMV688271 (pathogen box), Brilacidin (pandemic box), Hayatinine, and Curine (phytometabolites from C. pareira) were taken for cross-docking against 68 different malaria parasite proteins with their respective active sites well characterized. The co-crystallized ligand of each of these proteins was docked to its respective protein to generate docking scores that were used as cut-offs for our compounds. Each lead molecule was docked into the active sites of selected proteins, and the docking scores were computed. Out of the 68 proteins studied (Supplementary Table 4), the number of different protein-ligand complexes with docking scores $<$ that of 
co-crystallized ligand were 20 for MMV688271, 17 for Bedaquiline, 8 for Brilacidin, 7 for Hayatinine, and 10 for Curine (Supplementary Tables-5-9). Among the shortlisted proteins, three (Plasmepsins V, Cyclophilin, and Malaria Sporozoite Protein Uis3) were common for all five lead molecules (Fig-7b). These three targets are known to be expressed only in trophozoites and schizont stages ${ }^{46}$ (Fig-7a) and binding of the test molecules to them might explain their cidal activity towards mature stages of $P$. falciparum. We also identified proteins such as peptide deformylase, Pyruvoyl Tetrahydropterin Synthase (PTPS), and glutaredoxin 1 which are uniquely expressed in trophozoites to be the putative targets of test molecules (Fig-7a). In an attempt to find the binding affinity of our lead molecules to their putative target proteins, MMGBSA dG binding was computed. (Supplementary Tables 5-9). In all cases, dG binding was found to be $<-30$ $\mathrm{kcal} / \mathrm{mol}$ (Fig-7c). This low -ve score suggests that the proteins identified might indeed be the targets for our lead molecules. However extensive studies will be required to confirm the status of these proteins as drug targets for these molecules.

\section{In vivo toxicity and antimalarial study of Bedaquiline, and USINB4- 124-8}

USINB4-124-8 at $100 \mathrm{mg} / \mathrm{kg} \mathrm{b}$. wt. did not show any signs of acute toxicity (Supplementary Table 10) and till day 16 mice were as healthy as the control mice. Bedaquiline acute toxicity was not carried out as this molecule is already FDA approved for tuberculosis treatment. Treatment of $P$. berghei ANKA infected mice with vehicle solution (-ve control) led to increased fluctuations in body temperature and a decrease in mean body weight concomitant with the progressive increase in \% Parasitemia with a median survival of 19 days and death of all 7 mice by day 22. Likewise, USINB4-124-8 (100 mg/kg b. wt.) fed mice also showed no difference from -ve control in terms of survival, \% rise in parasitemia, fluctuation in body weight, and temperature (Fig-8). In contrast, Bedaquiline (50 mg/kg b. wt.) resulted in the complete suppression of \% Parasitemia by day 19 , reduced fluctuations in temperature and body weight as compared to -ve control, and survival of three out of seven mice till 34 days (Fig-8).

\section{Discussion}

Control measures against the vector Anopheles mosquito and extensive use of artemisinin-based combination therapy (ACT) against the parasite did result in a marked decrease in malaria cases in the last decade ${ }^{48}$. However, the surge in malaria cases in Asia as also in Africa which have reported resistance to CQ, sulfadoxine-pyrimethamine, ACT, and other antimalarial combinations, demands new antimalarials against new targets to combat the threat of drug-resistant strains. An emerging strategy to kill Plasmodium is to target its Achilles' heel, viz invasion by sporozoites into hepatocytes, merozoites into erythrocytes, and ookinetes into mosquito gut wall. As many proteins of the merozoites bear similarity with proteins found in sporozoites and gametocytes ${ }^{15,49}$, a small molecule preventing invasion by binding to a common target could block entry of malaria parasite into the safe milieu of different cells in man and mosquito. This could enable the immune system to kill the "out of cell" malaria parasite and not allow it to create havoc by the exponential rise in its numbers seen upon successful invasion into a cell. In the event of rapid death, resistance is not possible either. Thus, we aimed to block invasion so as not to give the parasite a chance for the exponential rise in percent Parasitemia that malaria parasite ensures from within the safe confines of the host cell. Among the major surface proteins of merozoite that have been targeted for both vaccine and drug development, the highly conserved glideosomal proteins have remained largely neglected ${ }^{50}$. These motor proteins are involved in the meticulously organized development of the inner membrane complex (IMC) that includes the IMC resident multiprotein complexes that are known to facilitate the highly efficient and extremely fast process of invasion by merozoites, sporozoites, and ookinetes. Among these proteins, glideosome associated protein 50 aka GAP50 is highly conserved in apicomplexan parasites and acts as an anchor for other motor

Page $12 / 27$ 
proteins. Further GAP50 bears low homology to human protein homologs ${ }^{47}$ which makes it a suitable target for drugs. The presence of conserved regions on the surface of $\mathrm{GAP}^{20} \mathrm{O}^{20}$, zygote motility inhibition by anti-GAP50 antibodies ${ }^{19}$, and the ability of GAP50 to bind human complement factor $\mathrm{H}^{51}$ to suggest that this protein is of vital importance to the parasite. Hence GAP50 is well suited as a target for screening the next generation of novel drugs against malaria.

The difficulty of targeting specific sites on GAP50 stems from the fact that since GAP50 is an anchor protein with no enzymatic activity, there is no knowledge of ligand binding sites and no known inhibitors against GAP50. In the absence of this vital knowledge, blind in silico docking of 951 compounds was done in parallel with screening these compounds using DSF. These two tools helped in hit enrichment in a high throughput manner allowing us to narrow down from 951 to 345 compounds for in vitro SPR and in vitro antiplasmodial activity. Further, even as the structural homology between GAP50 and hPAP (human purple acid phosphatases) was only $30 \% 20$, we selected only those compounds which showed Selectivity Indices > 100 against HUH 7 and HEK293 human cell lines. This stringent criterion helped eliminate all those compounds that might be toxic.

Using the filter of selectivity index, fourteen pathogen and pandemic box molecules were identified with resistance indices < 3. Notably, based on MMV classification of compounds ${ }^{52-54}$, some $(689437,019189,022029,688371,688271,000016$, and 000062) are already known for their antiprotozoal activity while others like Bedaquiline, 688775, 021660, and Brilacidin are known for antibacterial activity. Likewise, 639951,1782353 , and 642550 are well established as antiviral agents (www.mmv.org/mmv-open). Our work has for the first time identified Bedaquiline, Brilacidin, MMV642550, and MMV1782353 as anti-plasmodial. Amongst MMV FDA approved molecules (KD in $\mu \mathrm{M}$, parentheses), Mefloquine (40), Suramin (28.6), Bitertanol (0.333), Letermovir (19.2), Everolimus (0.257), Deferasirox (4.93), Valdecoxib (9.63), Ketoconazole (16.5), Ezetimibe (1.16), LED209 (2.62), Birinapant (12.4), Mgb Bp3 (14.8), Alexidine (27.0), Tipifarnib (52.2), Eberconazole (75.9), Ozanimod (76.5), Pentamidine (12.7), Rifampicin (0.116), Bedaquiline (9.27) and Brilacidin (2.81) have been identified as binders to GAP50.

Before understanding the modes of action of the above mentioned fourteen molecules, their $\mathrm{IC}_{50 \text { s }}$ against different asexual stages of parasite were determined and compounds with multi-stage activity particularly towards trophozoites and schizonts were prioritized for further investigations. This multi-stage activity assessment with special reference to the lowest $\mathrm{IC}_{50}$ observed at $[\mathrm{T} \diamond \mathrm{S}$ and $\mathrm{S} \diamond \mathrm{R}]$ transitions led us to look for various mechanisms that can explain their cidal activity. In this attempt, we observed that treatment with some of these compounds (Fig. 2) led to a significant increase in oxidant levels similar to what was observed upon treatments with ART/DHA. This suggested that these small molecules may target proteins involved in oxidant enhancing pathways like hemoglobin digestion which releases heme, mitochondrial electron transport chain or may cause inhibition of superoxide dismutases and

thioredoxin-dependent peroxidases ${ }^{43,55}$. Interestingly, between the structurally similar Hayatinine and Curine, it was only the latter that enhanced oxidant levels in the parasite. Challenge with Bedaquiline is known to cause an electroneutral uncoupling of respiration-driven ATP synthesis ${ }^{56}$, which can explain its effect in causing an increase in oxidant level in the parasite. Further, based on our cross-docking studies, Bedaquiline was seen binding with Glutaredoxin I protein (docking score -2.2, and MMGBSA dG binding $-30.82 \mathrm{kcal} / \mathrm{mol}$ ) which might be one of the mechanisms by which it may cause an increase in oxidant level. Brilacidin's prooxidant effect may be related to its ability to cause cellular stress by facilitating the accumulation of misfolded proteins in the endoplasmic reticulum ${ }^{57}$. Indeed the upregulation of various chaperones and proteases by Brilacidin ${ }^{57}$ indicates that cytoplasmic protein misfolding stress may be a contributor to the mechanism of action of this drug. On the one hand, since an increase in cellular oxidant levels can cause damage to cellular proteins, lipids, and nucleic acids, which is fatal to the parasite ${ }^{58,59}$, Plasmodium has evolved diverse ways to maintain this redox homeostasis ${ }^{60}$. On the other hand, a recent study by Egwu et. al ${ }^{61}$ has indicated superoxide to have a major role in the mechanism of action of several essential antimalarial drugs. Therefore, compounds showing a tendency to increase 
oxidants to levels that are beyond the capacity of the parasite's homeostatic ability can indeed increase cellular stress leading to the death of the parasite.

Since our screening of compounds was done using GAP50, which is expressed in the late trophozoite and schizont stages (30 - 35 h p.i) of Plasmodium and is involved in IMC formation ${ }^{13}$, we checked whether the inhibitors (Bedaquiline, Hayatinine, Curine, MMV688271, and Brilacidin) identified by us were able to prevent successful schizogony and egress of merozoites. Their inhibitory activity towards schizont rupture and invasion by merozoites was further confirmed by indirect immunofluorescence assay which showed pyknotic and surface attached merozoites (Fig. 3). Further, to find if an invasion was inhibited due to disruption of IMC, we did immunofluorescence-based confocal microscopy of developing schizonts in presence of sublethal $\left(2 x / 1.5 x \mathrm{IC}_{50}\right)$ concentration of compounds to study IMC formation using Phil 1 and GAP50 as IMC markers. Our results indicated that Brilacidin, and Hayatinine, which inhibited invasion, also caused deformation in IMC formation, leading to the fall in GAP50-Phil1 co-localization coefficient from 0.8 in untreated control to below 0.6 in treated cultures. On the other hand, the schizontocidal compounds Curine, Brilacidin and MMV688271, did not perturb IMC formation (P-value 0.88). MMV1782353 and MMV642550 which were found to prevent schizont rupture but not an invasion, were seen to prevent Phil1 and GAP50 association (P-value $<0.6)$.

Data on the in silico binding lead molecules, i.e. MMV688271, Hayatinine, Curine, Bedaquiline, and Brilacidin with GAP50 has shed light on the binding site residues, which can help in the chemical synthetic tweaking of these inhibitors to increase their potency and selectivity. Interestingly while Hayatinine and MMV688271 binding sites on GAP50 were found to consist predominantly of non-polar residues, the sites that recognized Bedaquiline, MMV642550 and Brilacidin were rich in polar residues. In contrast, the MMV688271 binding site contained an equal proportion of polar and non-polar residues. The involvement of water molecules in stabilizing Hayatinine, Curine, MMV688271, MMV642550, and Brilacidin binding in their respective grooves shows the importance of the water bridges present in these regions. It is tempting to hypothesize that binding by the above-mentioned lead compounds may perturb the protein-protein interactions that are the hallmarks of the multiprotein complexes found in the IMC. Also, it was interesting to observe that with Curine and MMV688271 as also MMV642550 and USINB4-124-8 sharing the same binding sites, the eight different GAP50 binders were found to bind at six different binding sites The binding of all schizontocidal molecules (Curine, Brilacidin, and 688271) at the top left edge of the molecule and binding of invasion inhibitory molecules (Hayatinine and Bedaquiline) at bottom right seems to suggest anatomical zones in GAP50 catering to specific functions. However, this needs further confirmation from crystallographic studies (Fig. 2).

In a bid to explore what proteins other than GAP50 may bind to these lead compounds, we have found that these compounds may have alternate protein targets besides GAP50. The in silico binding of our lead compounds to one or more of these putative targets may well be the explanation for their multi-stage activity. Coupled with over hundred-fold selectivity, the presence of multi targets in malaria proteome is a plus point for these compounds since multi-targeting drugs could have low chances of losing efficacy due to the development of resistance ${ }^{62}$.

The longer half-life of small molecules in vivo is usually associated with their ability to bind with serum proteins or uptake in cells from where they are released in small amounts over a period of time ${ }^{63}$. Since malaria parasites target RBCs, we explored if healthy RBCs could be preloaded with some of our lead compounds such that these "loaded" RBCs could gain competence to restrict the growth of malaria parasites. Such retention of compounds in RBCs offers a prophylactic strategy that can be useful for passengers prone to traveller's malaria. Our data showed Bedaquiline as the most promising molecule that is retained by RBCs in concentrations sufficient at preventing the growth of the parasite. This result is not surprising since Bedaquiline is known to bind with plasma proteins which increases its half-life to $>5$ months ${ }^{64}$. Similar but slightly less potent effects were also observed in RBCs preloaded with MMV642550, Brilacidin, and MMV688271. 
The finding of potent antiplasmodial activity in Bedaquiline is highly significant since it is a drug already in use against MDR TB ${ }^{65}$. This molecule has a selectivity of over 20,000 for bacterial ATP synthase ${ }^{66}$ over mammalian ATP synthase. Our finding of Bedaquiline's ability to prevent schizogony and subsequent invasion by merozoites became more interesting when we found that Bedaquiline could cure the mice of malaria infection with mitigation of associated symptoms like pyrexia and weight loss. However, in some Bedaquiline fed mice, there was development of malaria leading to death. This is most likely due to pharmacokinetic differences ${ }^{64}$ in laboratory mice with some mice reducing the drug level faster than others. Bedaquiline is known to be metabolized by CYP3A4 into N-monodesmethyl (M2) which has less therapeutic activity as compared with Bedaquiline ${ }^{67}$. Since Bedaquiline availability is dose dependent ${ }^{64}$, its efficacy against malaria could be increased using a higher dose of this molecule than the $50 \mathrm{mg} / \mathrm{Kg}$ used by us.

As a bonus, we found that combinations of MMV688271, Brilacidin, Hayatinine, Bedaquiline, and Curine with standard antimalarial drugs in specific ratios showed impressive synergistic to additive to antagonistic effects. This seems to open new prospects for use of novel synergistic combinations for the formulation of new ACTs. In conclusion, we have identified GAP50 binder molecules and predicted ligand binding sites on GAP50, which can be taken for future drug optimization and development as novel drugs against malaria. Further, the identification of FDA approved Bedaquiline and Brilacidin as antimalarials might expedite their development as partner drugs with ART in Artemisinin combination therapy (ACTs).

\section{Abbreviations}

ART: Artemisinin, DHA: Dihydro Artemisinin, $\mathrm{CC}_{50}$ : concentration that causes $50 \%$ growth inhibition in human cell lines, ES: Early Schizont, ET: Early Trophozoite, GAP: glideosome associated protein, $\mathrm{IC}_{50}$ : concentration that causes $50 \%$ growth inhibition. IMC: Inner membrane complex, LS: Late Schizont, LT: Late Trophozoite, MFQ: mefloquine, MMGBSA: Molecular Mechanics Generalized Born Surface Area, MMV: Medicines for Malaria Venture, p.i: post-infection, PYR: pyrimethamine, R: Rings, RBC: Red blood cell, RI: resistance index, SPR: Surface Plasmon Resonance, S: Schizonts, SI: selectivity index, T: Trophozoites.

\section{Declarations}

\section{Acknowledgment}

We are thankful to MMV for providing pathogen and pandemic box compounds. We are grateful to Dr. Pawan Malhotra for providing us with the Phil1 and GAP50 antibody, Dr. Purnima and Swati Gupta for helping with confocal experiments. Thanks to Dr. Arockiasamy Arulandu and Shobhan Kuila for helping with SPR and in silico Schrödinger work.

\section{Funding}

PA and SK acknowledge the financial support received from the Department of Biotechnology, Government of India and CSIR, New Delhi, respectively, in the form of JRF and SRF fellowship. This work was financially supported by ICGEB, New Delhi.

\section{Disclosure of Interest}

The authors declare no competing interests and declare that work done in this manuscript is conceptualized and carried out by PA and DS. Antimalarial activity was evaluated with prior approval (ICGEB/IAEC/30012021/MPB-8) and in accordance with ICGEB animal ethical committee. 


\section{Author contribution}

PA and DS contributed to the conceptualization of the idea and writing of the manuscript. All experiments and data analysis were done by PA. SK and US provided pure synthetic quinoline derivatives and phytometabolites for this work.

\section{Ethics declaration}

In vivo mice experimentation study was conducted as per ARRIVE 2.0 guideline with prior approval from ICGEB institutional animals' ethics committee (approval number ICGEB/IAEC/30012021/MPB-8). In vivo mice toxicity study was done as per OECD 423 guideline.

\section{Statistical analysis}

Statistical analysis was carried out using GraphPad Prism (version 5) software.

\section{References}

1. Mishra, M., Mishra, V. K., Kashaw, V., lyer, A. K. \& Kashaw, S. K. Comprehensive review on various strategies for antimalarial drug discovery. Eur. J. Med. Chem. 125, 1300-1320 (2017).

2. Blank, A. et al. Immunization with full-length Plasmodium falciparum merozoite surface protein 1 is safe and elicits functional cytophilic antibodies in a randomized first-in-human trial. npj Vaccines 5, 1-15 (2020).

3. Genton, B. et al. Safety and immunogenicity of a three-component blood-stage malaria vaccine (MSP1, MSP2, RESA) against Plasmodium falciparum in Papua New Guinean children. Vaccine 22, 30-41 (2003).

4. Thera, M. A. et al. A Field Trial to Assess a Blood-Stage Malaria Vaccine. N. Engl. J. Med. 365, 1004-1013 (2011).

5. Payne, R. O. et al. Human vaccination against RH5 induces neutralizing antimalarial antibodies that inhibit RH5 invasion complex interactions. JCl Insight 2, (2017).

6. Koram, K. A. et al. Safety and immunogenicity of EBA-175 RII-NG Malaria vaccine administered intramuscularly in semi-immune adults: A Phase 1, Double-blinded placebo controlled dosage escalation study. PLoS One 11, (2016).

7. Parkyn Schneider, M. et al. Disrupting assembly of the inner membrane complex blocks Plasmodium falciparum sexual stage development. PLoS Pathog. 13, e1006659 (2017).

8. Ferreira, J. L. et al. The Dynamic Roles of the Inner Membrane Complex in the Multiple Stages of the Malaria Parasite. Frontiers in Cellular and Infection Microbiology vol. 10 (2021).

9. Opitz, C. \& Soldati, D. 'The glideosome': A dynamic complex powering gliding motion and host cell invasion by Toxoplasma gondii. Mol. Microbiol. 45, 597-604 (2002).

10. Boucher, L. E. \& Bosch, J. The apicomplexan glideosome and adhesins - Structures and function. J. Struct. Biol. 190, 93-114 (2015).

11. Gaskins, E. et al. Identification of the membrane receptor of a class XIV myosin in Toxoplasma gondii. J. Cell Biol. 165, 383-393 (2004).

12. Dearnley, M. K. et al. Origin, composition, organization and function of the inner membrane complex of Plasmodium falciparum gametocytes. J. Cell Sci. 125, 2053-2063 (2012).

13. Yeoman, J. A. et al. Tracking glideosome-associated protein 50 reveals the development and organization of the inner membrane complex of Plasmodium falciparum. Eukaryot. Cell 10, 556-564 (2011).

14. Cowman, A. F., Berry, D. \& Baum, J. The cellular and molecular basis for malaria parasite invasion of the human red blood cell. J. Cell Biol. 198, 961-971 (2012). 
15. Baum, J. et al. A conserved molecular motor drives cell invasion and gliding motility across malaria life cycle stages and other apicomplexan parasites. J. Biol. Chem. 281, 5197-5208 (2006).

16. Bergman, L. W. et al. Myosin A tail domain interacting protein (MTIP) localizes to the inner membrane complex of Plasmodium sporozoites. Journal of Cell Science vol. 116 39-49 (2003).

17. Soldati-Favre, D. Molecular dissection of host cell invasion by the Apicomplexans: The glideosome. Parasite 15, 197205 (2008).

18. Cowman, A. F. et al. Functional analysis of proteins involved in Plasmodium falciparum merozoite invasion of red blood cells. FEBS Lett. 476, 84-88 (2000).

19. Beiss, V. et al. Plant expression and characterization of the transmission-blocking vaccine candidate PfGAP50. BMC Biotechnol. 15, 108 (2015).

20. Bosch, J., Paige, M. H., Vaidya, A. B., Bergman, L. W. \& Hol, W. G. J. Crystal structure of GAP50, the anchor of the invasion machinery in the inner membrane complex of Plasmodium falciparum. J. Struct. Biol. 178, 61-73 (2012).

21. Kumar, I. et al. Photocatalytic Unsymmetrical Coupling of 2-Substituted Quinolines: Synthesis and Evaluation of the Antiplasmodial Potential of $\beta$-Norbenzomorphan Frameworks. ACS Sustain. Chem. Eng. 8, 12902-12910 (2020).

22. Bhatt, V. et al. Chemical profiling and quantification of potential active constituents responsible for the antiplasmodial activity of Cissampelos pareira. J. Ethnopharmacol. 262, 113185 (2020).

23. Madhavi Sastry, G., Adzhigirey, M., Day, T., Annabhimoju, R. \& Sherman, W. Protein and ligand preparation: Parameters, protocols, and influence on virtual screening enrichments. J. Comput. Aided. Mol. Des. 27, 221-234 (2013).

24. Friesner, R. A. et al. Extra precision glide: Docking and scoring incorporating a model of hydrophobic enclosure for protein-ligand complexes. J. Med. Chem. 49, 6177-6196 (2006).

25. Lyne, P. D., Lamb, M. L. \& Saeh, J. C. Accurate prediction of the relative potencies of members of a series of kinase inhibitors using molecular docking and MM-GBSA scoring. J. Med. Chem. 49, 4805-4808 (2006).

26. Bowers, K. J. et al. Scalable Algorithms for Molecular Dynamics Simulations on Commodity Clusters. in 43-43 (Institute of Electrical and Electronics Engineers (IEEE), 2007). doi:10.1109/sc.2006.54.

27. Huynh, K. \& Partch, C. L. Analysis of protein stability and ligand interactions by thermal shift assay. Curr. Protoc. protein Sci. 79, 28.9.1-28.9.14 (2015).

28. Trager, W. \& Jensen, J. B. Human malaria parasites in continuous culture. Science (80- ). 193, 673-675 (1976).

29. Smilkstein, M., Sriwilaijaroen, N., Kelly, J. X., Wilairat, P. \& Riscoe, M. Simple and Inexpensive Fluorescence-Based Technique for High-Throughput Antimalarial Drug Screening. Antimicrob. Agents Chemother. 48, 1803-1806 (2004).

30. Mosmann, T. Rapid colorimetric assay for cellular growth and survival: Application to proliferation and cytotoxicity assays. J. Immunol. Methods 65, 55-63 (1983).

31. Ribaut, C. et al. Concentration and purification by magnetic separation of the erythrocytic stages of all human Plasmodium species. Malar. J. 7, 1-5 (2008).

32. Saini, E. et al. Plasmodium falciparum PhIL1-associated complex plays an essential role in merozoite reorientation and invasion of host erythrocytes. PLoS Pathogens vol. 17 1-20 (2021).

33. Thapar, M. M., Gupta, S., Spindler, C., Wernsdorfer, W. H. \& Björkman, A. Pharmacodynamic interactions among atovaquone, proguanil and cycloguanil against Plasmodium falciparum in vitro. Trans. R. Soc. Trop. Med. Hyg. 97, 331-337 (2003).

34. Meletiadis, J., Pournaras, S., Roilides, E. \& Walsh, T. J. Defining fractional inhibitory concentration index cutoffs for additive interactions based on self-drug additive combinations, Monte Carlo simulation analysis, and in vitro-in vivo correlation data for antifungal drug combinations against Aspergillus fumi. Antimicrob. Agents Chemother. 54, 602609 (2010). 
35. OECD. Test No. 423: Acute Oral toxicity - Acute Toxic Class Method. Oecd Guidel. Test. Chem. 1-14 (2002) doi:10.1787/9789264071001-en.

36. Ryley, J. F. \& Peters, W. The antimalarial activity of some quinolone esters. Ann. Trop. Med. Parasitol. 64, 209-222 (1970).

37. Sink, R., Gobec, S., Pecar, S. \& Zega, A. False Positives in the Early Stages of Drug Discovery. Curr. Med. Chem. 17, 4231-4255 (2010).

38. Gao, K., Oerlemans, R. \& Groves, M. R. Theory and applications of differential scanning fluorimetry in early-stage drug discovery. Biophysical Reviews vol. 12 85-104 (2020).

39. Davis, B. J. \& Erlanson, D. A. Learning from our mistakes: The 'unknown knowns' in fragment screening. Bioorganic and Medicinal Chemistry Letters vol. 23 2844-2852 (2013).

40. Bakhtiar, R. Surface plasmon resonance spectroscopy: A versatile technique in a biochemist's toolbox. J. Chem. Educ. 90, 203-209 (2013).

41. Bozdech, Z. et al. Expression profiling of the schizont and trophozoite stages of Plasmodium falciparum with a longoligonucleotide microarray. Genome Biol. 4, 1-15 (2003).

42. Kavishe, R. A., Koenderink, J. B. \& Alifrangis, M. Oxidative stress in malaria and artemisinin combination therapy: Pros and Cons. FEBS J. 284, 2579-2591 (2017).

43. Müller, S. Redox and antioxidant systems of the malaria parasite Plasmodium falciparum. Mol. Microbiol. 53, 12911305 (2004).

44. Boyle, M. J., Richards, J. S., Gilson, P. R., Chai, W. \& Beeson, J. G. Interactions with heparin-like molecules during erythrocyte invasion by Plasmodium falciparum merozoites. Blood 115, 4559-4568 (2010).

45. Saini, E. et al. Photosensitized INA-Labelled protein 1 (PhIL1) is novel component of the inner membrane complex and is required for Plasmodium parasite development. Sci. Rep. 7, 1-11 (2017).

46. Toenhake, C. G. et al. Chromatin Accessibility-Based Characterization of the Gene Regulatory Network Underlying Plasmodium falciparum Blood-Stage Development. Cell Host Microbe 23, 557-569.e9 (2018).

47. Singh, G. P. Conservation of gene essentiality in Apicomplexa and its application for prioritization of anti-malarial drug targets. F1000Research 6, 1-7 (2017).

48. WHO. The 'World malaria report 2019' at a glance. December 2019 vol. 2018 1-10 https://www.who.int/newsroom/feature-stories/detail/world-malaria-report-2019 (2019).

49. Fowler, R. E., Margos, G. \& Mitchell, G. H. The Cytoskeleton and Motility in Apicomplexan Invasion. Adv. Parasitol. 56, 213-263 (2003).

50. Burns, A. L. et al. Targeting malaria parasite invasion of red blood cells as an antimalarial strategy. FEMS Microbiol. Rev. 43, 223-238 (2019).

51. Kennedy, A. T. et al. Recruitment of Factor $\mathrm{H}$ as a Novel Complement Evasion Strategy for Blood-Stage Plasmodium falciparum Infection. J. Immunol. 196, 1239-1248 (2016).

52. Van Voorhis, W. C. et al. Open Source Drug Discovery with the Malaria Box Compound Collection for Neglected Diseases and Beyond. PLoS Pathog. 12, e1005763 (2016).

53. Samby, K., Willis, P. A., Burrows, J. N., Laleu, B. \& Webborn, P. J. H. Actives from MMV Open Access Boxes? A suggested way forward. PLoS Pathogens vol. 17 e1009384 (2021).

54. Veale, C. G. L. Unpacking the Pathogen Box-An Open Source Tool for Fighting Neglected Tropical Disease. ChemMedChem vol. 14 386-453 (2019).

55. Becker, K. et al. Oxidative stress in malaria parasite-infected erythrocytes: Host-parasite interactions. Int. J. Parasitol. 34, 163-189 (2004).

56. Hards, K. et al. Bactericidal mode of action of bedaquiline. J. Antimicrob. Chemother. 70, 2028-2037 (2015). 
57. Mensa, B., Howell, G. L., Scott, R. \& DeGrado, W. F. Comparative mechanistic studies of brilacidin, daptomycin, and the antimicrobial peptide LL16. Antimicrob. Agents Chemother. 58, 5136-5145 (2014).

58. Egwu, C. O. et al. Resistance to artemisinin in falciparum malaria parasites: A redox-mediated phenomenon. Free Radic. Biol. Med. 179, 317-327 (2022).

59. Gopalakrishnan, A. M. \& Kumar, N. Antimalarial action of artesunate involves DNA damage mediated by reactive oxygen species. Antimicrob. Agents Chemother. 59, 317-325 (2015).

60. Jortzik, E. \& Becker, K. Thioredoxin and glutathione systems in Plasmodium falciparum. Int. J. Med. Microbiol. 302, 187-194 (2012).

61. Egwu, C. O. et al. Superoxide: A major role in the mechanism of action of essential antimalarial drugs. Free Radic. Biol. Med. 167, 271-275 (2021).

62. Gelb, M. H. Drug discovery for malaria: a very challenging and timely endeavor. Curr. Opin. Chem. Biol. 11, 440-445 (2007).

63. Sleep, D., Cameron, J. \& Evans, L. R. Albumin as a versatile platform for drug half-life extension. Biochimica et Biophysica Acta - General Subjects vol. 1830 5526-5534 (2013).

64. van Heeswijk, R. P. G., Dannemann, B. \& Hoetelmans, R. M. W. Bedaquiline: A review of human pharmacokinetics and drug-drug interactions. J. Antimicrob. Chemother. 69, 2310-2318 (2014).

65. Pontali, E., Sotgiu, G., D’Ambrosio, L., Centis, R. \& Migliori, G. B. Bedaquiline and multidrug-resistant tuberculosis: A systematic and critical analysis of the evidence. European Respiratory Journal vol. 47 394-402 (2016).

66. Matteelli, A., Carvalho, A. C. C., Dooley, K. E. \& Kritski, A. TMC207: The first compound of a new class of potent antituberculosis drugs. Future Microbiology vol. 5 849-858 (2010).

67. Svensson, E. M., Dosne, A. G. \& Karlsson, M. O. Population Pharmacokinetics of Bedaquiline and Metabolite M2 in Patients with Drug-Resistant Tuberculosis: The Effect of Time-Varying Weight and Albumin. CPT Pharmacometrics Syst. Pharmacol. 5, 682-691 (2016).

\section{Figures}


a.

Molecules from MMV Pathogen box (400) and Pandemic box (400)

+ lab synthesized compounds (140) + lab isolated natural products (11)

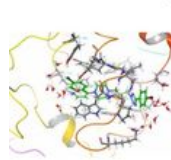

GAP50 binding in silico (Schrödinger) and in solution (DSF)

Validation of binding with GAP50 by SPR @ $50 \mu \mathrm{M}$

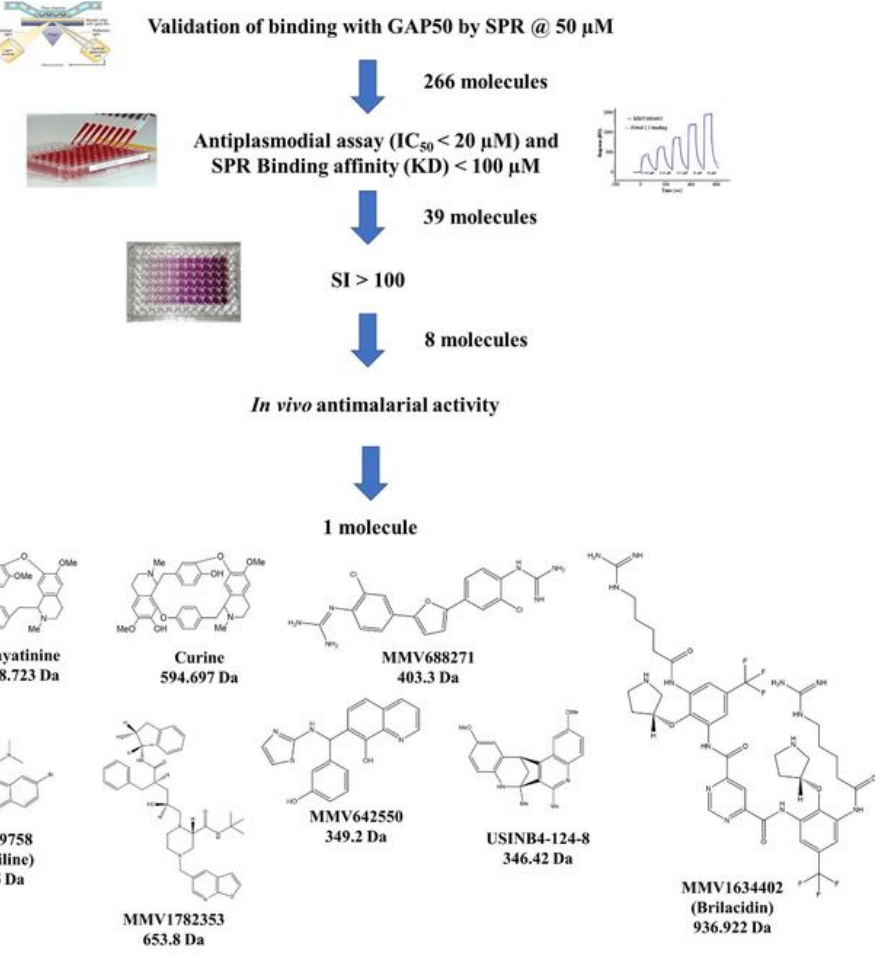

b.

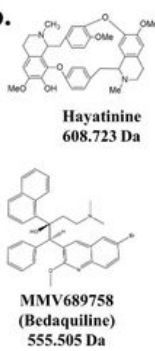

936.922 Da

\section{Figure 1}

Selection of molecules at successive stages of molecular, cellular, and in vivo animal screenings. (a) Flow chart showing the pool of 951 molecules coming from diverse sources and the progressively decreasing numbers of shortlisted molecules at successive stages of different kinds of screens (b) Structure of the eight PfGAP50 binders hit molecules with anti-plasmodial $\mathrm{IC}_{50}<3 \mu \mathrm{M}$ and Selectivity Indices $\geq 100$. Hayatinine and Curine are isolated from Cissampelos pareira, USINB4-124-8 is an azepino quinoline, the remaining molecules that have come from MMV pathogen and pandemic boxes are of diverse chemical natures including piperazine carboxamide (MMV1782353), pyrimidine dicarboxamide (Brilacidin), Benzimidazole (MMV642550), quinoline (Bedaquiline), and 2,5-diphenylfuran (MMV688271). 


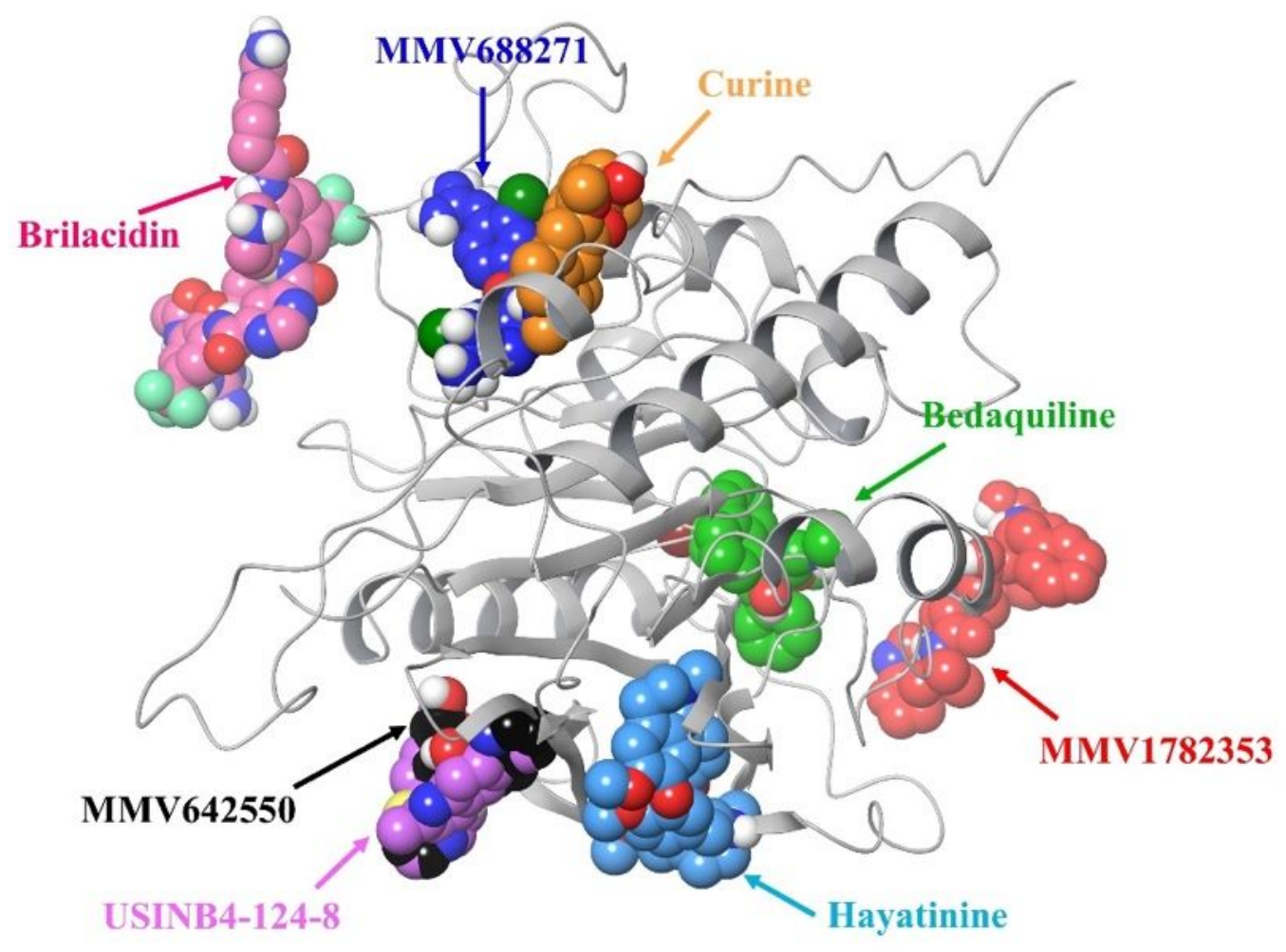

Figure 2

Representation of predicted binding sites of lead molecules against GAP50. Eight most promising molecules identified at the end of all filters used were found to bind to GAP50 at six different sites. As shown in Results, Curine, Brilacidin, and MMV688271(all binding at the top left edge of the molecule) were found to be schizontocidal, Hayatinine and Bedaquiline (binding at the bottom right) caused inhibition of invasion, while 1782353 and 642550 were schizontostatic since their withdrawal allowed the treated schizonts to egress and merozoites to invade. 
(a)
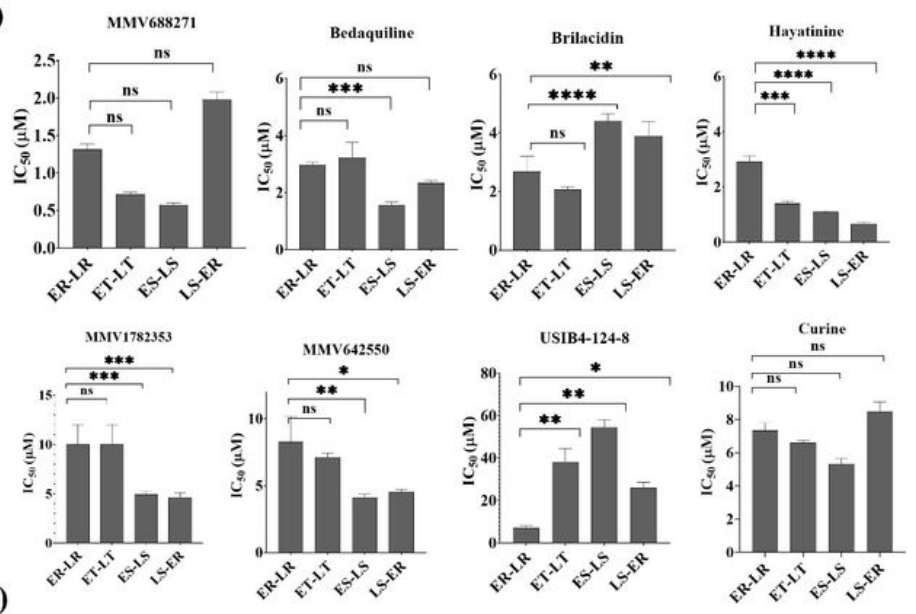

(b)
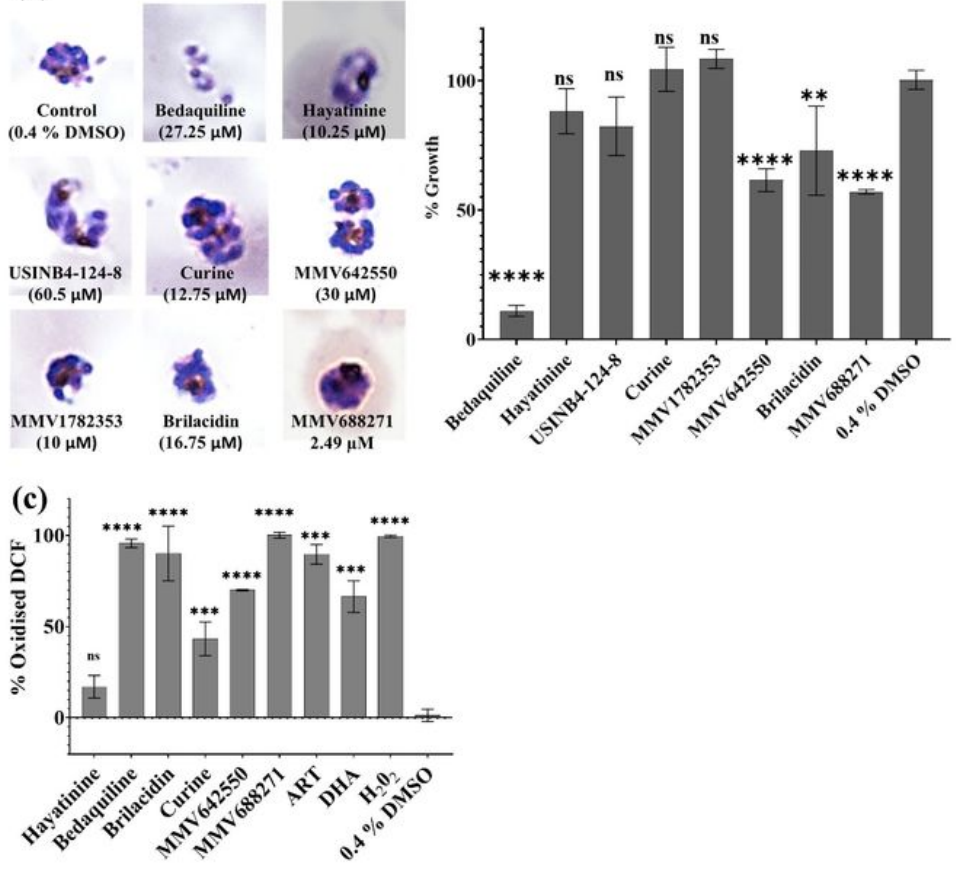

Figure 3

Mechanistic action of GAP50 binders. (a) IC 50 of GAP50 binders against different stages of Plasmodium. E: early, L: late, R: rings, T: trophozoites, S: schizonts. (b) Effect of preincubation of healthy RBCs with lead antiplasmodial molecules (10x $\mathrm{IC}_{50}$ ) on subsequent parasite development. The histogram on the right shows \% growth as measured by SYBR green assay with reference to control $0.4 \%$ DMSO, (c) \% Oxidised DCF upon incubation with each lead molecule at $2 \times I_{50}$ [ETàLT]. All three panels are showing the mean and standard deviation of experiments done in triplicate. In all three panels, P values are: $<0.0212(*),<0.0082(* \star),<0.0008(\star \star \star)$, and $<0.0001(\star \star \star \star)$ while "ns" denotes not significant. 

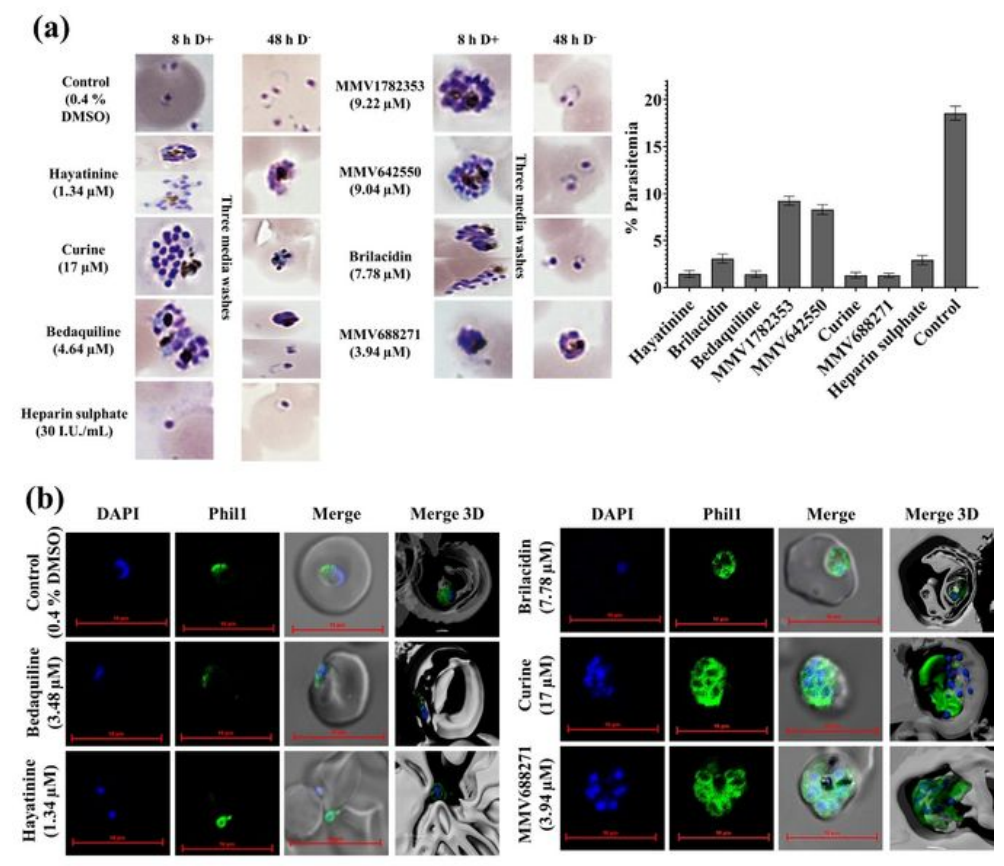

\section{Figure 4}

Effects of GAP50 binders on schizont egress and merozoite invasion. (a) shows treatment of segmental stage schizont for $8 \mathrm{~h}$ with $2 \mathrm{xIC}_{50}$ (LSàER) followed by replacement of test molecules and growing parasites in cRPMI for the next $48 \mathrm{~h}$. Left and right-hand panels show microscopic evaluation and \% parasitemia calculated by FACS $\left(10^{5}\right.$ cells counted) analysis done at the end of $56 \mathrm{~h}\left(8^{\mathrm{D}+}\right.$ and $\left.48^{\mathrm{D}-}\right)$ respectively. Heparin sulphate, a known inhibitor of invasion was used as a positive control. (b) shows DAPI and immunofluorescence staining of $8 \mathrm{~h}$ test molecule treated segmental schizonts. Briefly, parasites were treated with test molecules selected from panel (a), followed by fixation and staining with DAPI (5 $\mu \mathrm{g} / \mathrm{mL}$ ) and anti-Phil1 antibody raised in rabbit followed by staining with Alexa 488 fluorophore-conjugated anti-rabbit antibody. Notice the Phil1 staining inside the cell in control vs on the periphery in Bedaquiline and Hayatinine treated cultures and the remaining three schizontocidal molecules (Curine, Brilacidin, and MMV688271) exhibiting massive schizont staining. 


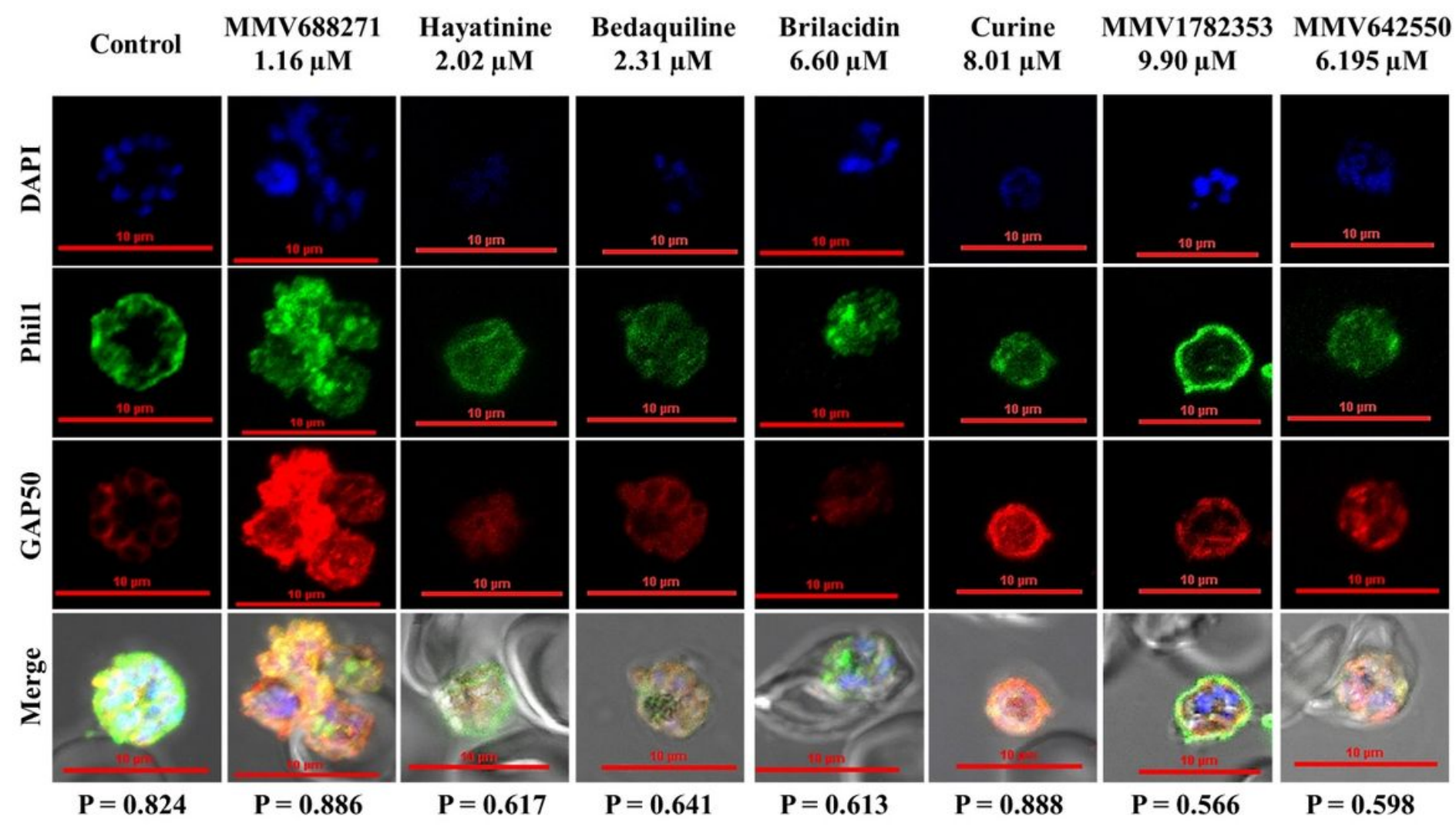

Figure 5

Effect of test molecules on IMC formation using immunostaining of Phil1 and GAP50 as IMC markers. Schizonts (34 to $36 \mathrm{~h} \mathrm{p.i}$ ) were first treated with sub-lethal concentration $\left(2 \mathrm{x} / 1.5 \mathrm{x} \mathrm{IC}_{50}\right.$ [ESà LS] ) of test molecules for $12 \mathrm{~h}$. The treated cultures were then subjected to DAPI staining (Blue) and antibody-based staining of Phil 1 (Green) and GAP50 (Red) as described in the method. The bottom panel shows a merge of all three top panels. The DAPI and immune stained samples were examined by confocal imaging to find the effect of test molecules on the colocalization of these two proteins. $0.4 \%$ DMSO was used as a control. P values at the bottom are Pearson correlation coefficients. Scale: $10 \mu \mathrm{M}$. 

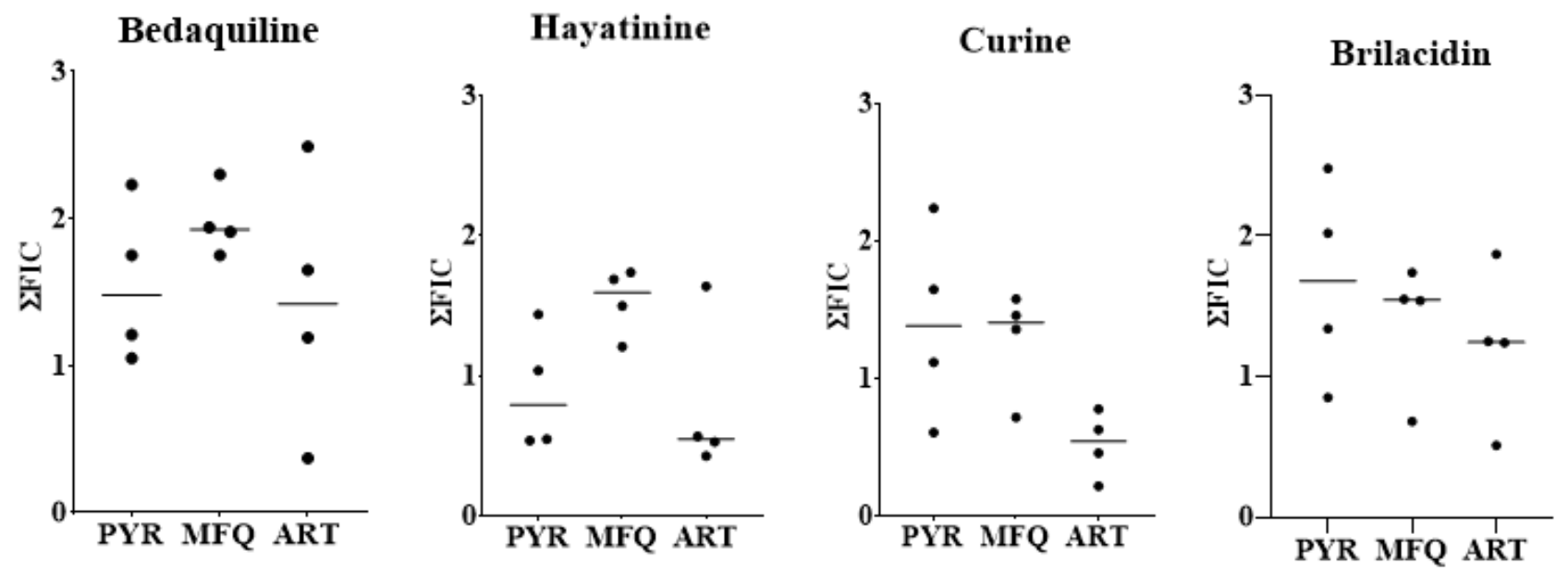

MMV688271

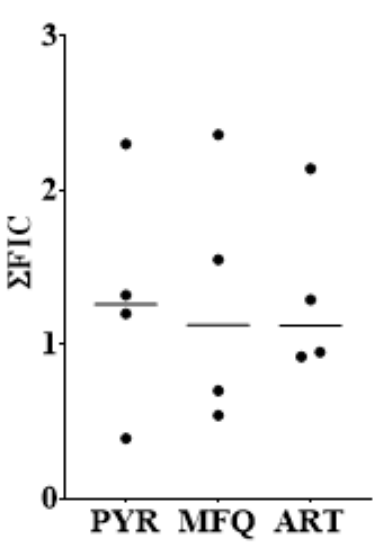

MMV642550

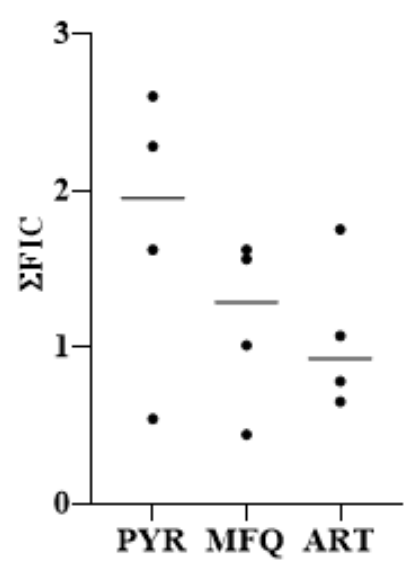

USINB4-124-8

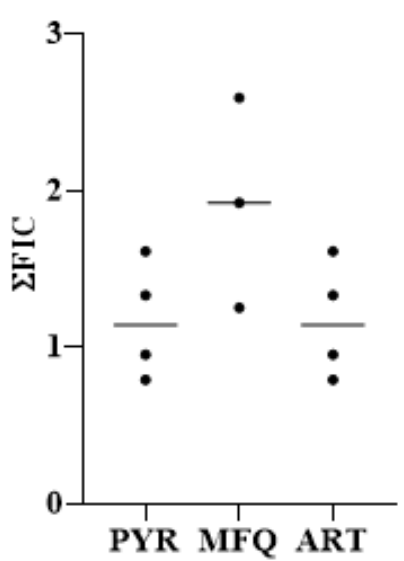

Figure 6

Graphical representation of $\sum$ FIC values of GAP50 binders with PYR, MFQ, and ART. Each dot represents an $\sum$ FIC of an individual ratio, with horizontal bars showing the mean values. Note the average $\sum$ FIC values of $\sim 0.5$ seen in combinations of Hayatinine and Curine with Artemisinin indicating strong synergy. Note: Individual FIC and $\sum$ FIC for each combination is provided in supplementary table 3. 


\begin{tabular}{|c|c|c|c|c|}
\hline Serial no & PDB id & Protein & Stage expression & Compound \\
\hline 1 & 1LS5 & Plasmepsin IV & $\begin{array}{l}\text { Rings and } \\
\text { merozites }\end{array}$ & $\begin{array}{c}\text { Bedaquiline, Brilacidin, Hayatinine, } \\
\text { Curine, MMV688271 }\end{array}$ \\
\hline 2 & IQNG & Cyclophilin & Schizonts & $\begin{array}{l}\text { Bedaquiline, Brilacidin, Hayatinine, } \\
\text { Curine, MMV688271 }\end{array}$ \\
\hline 3 & 2VWA & $\begin{array}{c}\text { Malaria Sporozoite } \\
\text { Protein Uis3 }\end{array}$ & Schizonts & $\begin{array}{c}\text { Bedaquiline, Brilacidin, Hayatinine, } \\
\text { Curine, MMV688271 }\end{array}$ \\
\hline 4 & 1RL4 & Peptide Deformylase & $\begin{array}{c}\text { Trophozoites, } \\
\text { Gametocyte stage V }\end{array}$ & $\begin{array}{l}\text { Bedaquiline, Brilacidin, Curine, } \\
\text { MMV688271 }\end{array}$ \\
\hline 5 & $1 Y 13$ & $\begin{array}{c}\text { Pyruvoyl } \\
\text { Tetrahydropterin } \\
\text { Synthase(PTPS) }\end{array}$ & Trophozoites & $\begin{array}{l}\text { Bedaquiline, Hayatinine, Curine, } \\
\text { MMV688271 }\end{array}$ \\
\hline 6 & $1 \mathrm{Z} 6 \mathrm{G}$ & Guanylate Kinase & $\begin{array}{c}\text { Late rings and } \\
\text { Trophozites }\end{array}$ & $\begin{array}{c}\text { Bedaquiline, Hayatinine, Curine, } \\
\text { MMV688271 }\end{array}$ \\
\hline 7 & 3PEH & HSP90 & Trophozoites & $\begin{array}{l}\text { Bedaquiline, Hayatinine, Curine, } \\
\text { MMV688271 }\end{array}$ \\
\hline 8 & $3 \mathrm{AZB}$ & $\begin{array}{l}\text { Beta-Hydroxyacyl-Acyl } \\
\text { Carrier Protein } \\
\text { Dehydratase }\end{array}$ & Rings & Bedaquiline, Hayatinine, MMV688271 \\
\hline 9 & $3 \mathrm{QVI}$ & $\begin{array}{c}\text { Histo-Aspartic Protease } \\
\text { (Hap) }\end{array}$ & Rings & Bedaquiline, Brilacidin, Curine \\
\hline 10 & 4MZB & $\begin{array}{l}\text { PfGrxl (glutaredoxin } \\
\text { 1) }\end{array}$ & Trophozoties & Bedaquiline, Curine, MMV688271 \\
\hline 11 & $2 \mathrm{PMO}$ & Ser/Thr protein kinase & $\begin{array}{c}\text { Trophozoites and } \\
\text { Schizonts }\end{array}$ & Bedaquiline, MMV688271 \\
\hline 12 & $2 \mathrm{YOG}$ & Thymidylate Kinase & $\begin{array}{c}\text { Schizonts, } \\
\text { Gametocytes II, V }\end{array}$ & Bedaquiline, Curine \\
\hline 13 & $3 \mathrm{CO} 2$ & Aquaglyceroporin & Schizonts & Bedaquiline, Brilacidin \\
\hline 14 & $3 \mathrm{~K} 7 \mathrm{Y}$ & $\begin{array}{c}\text { Aspartate } \\
\text { Aminotransferase }\end{array}$ & Rings, Trophozoites & Bedaquiline, MMV688271 \\
\hline
\end{tabular}
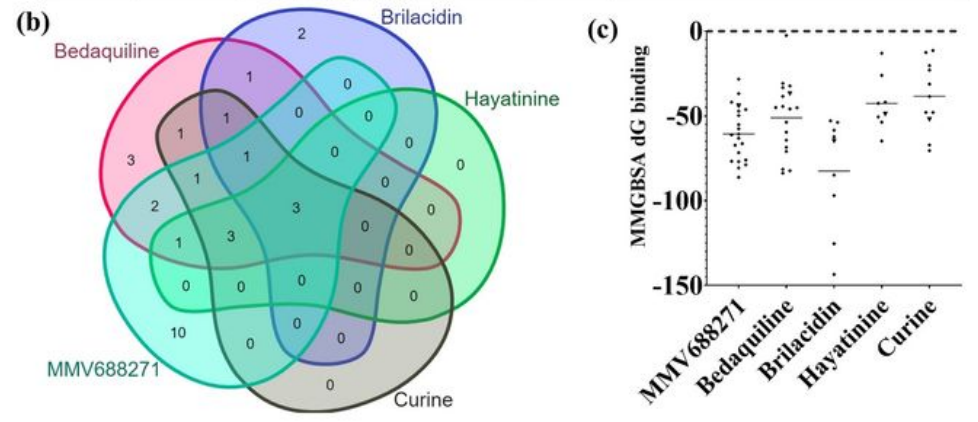

\section{Figure 7}

Cross-docking analysis of invasion inhibitory molecules. (a) table showing protein targets from malaria parasite proteome that are common for the lead molecules, Stage of expression for target proteins was taken from Singh et.al ${ }^{47}$. (b) Venn diagram representation to show number of common targets. Note, 3 proteins are common to Bedaquiline, Brilacidin, MMV688271, Curine, and Hayatinine. Unique proteins observed were 3 in Bedaquiline, 10 in MMV688271, 2 in Brilacidin, and none in the case of Hayatinine and Curine. (c) shows MMGBSA dG binding observed for individual ligands with different proteins of the malaria parasite. Each dot represents a dG binding value of a single protein-ligand complex. Horizontal bars represent the mean dG overall protein-ligand complexes. 
a.
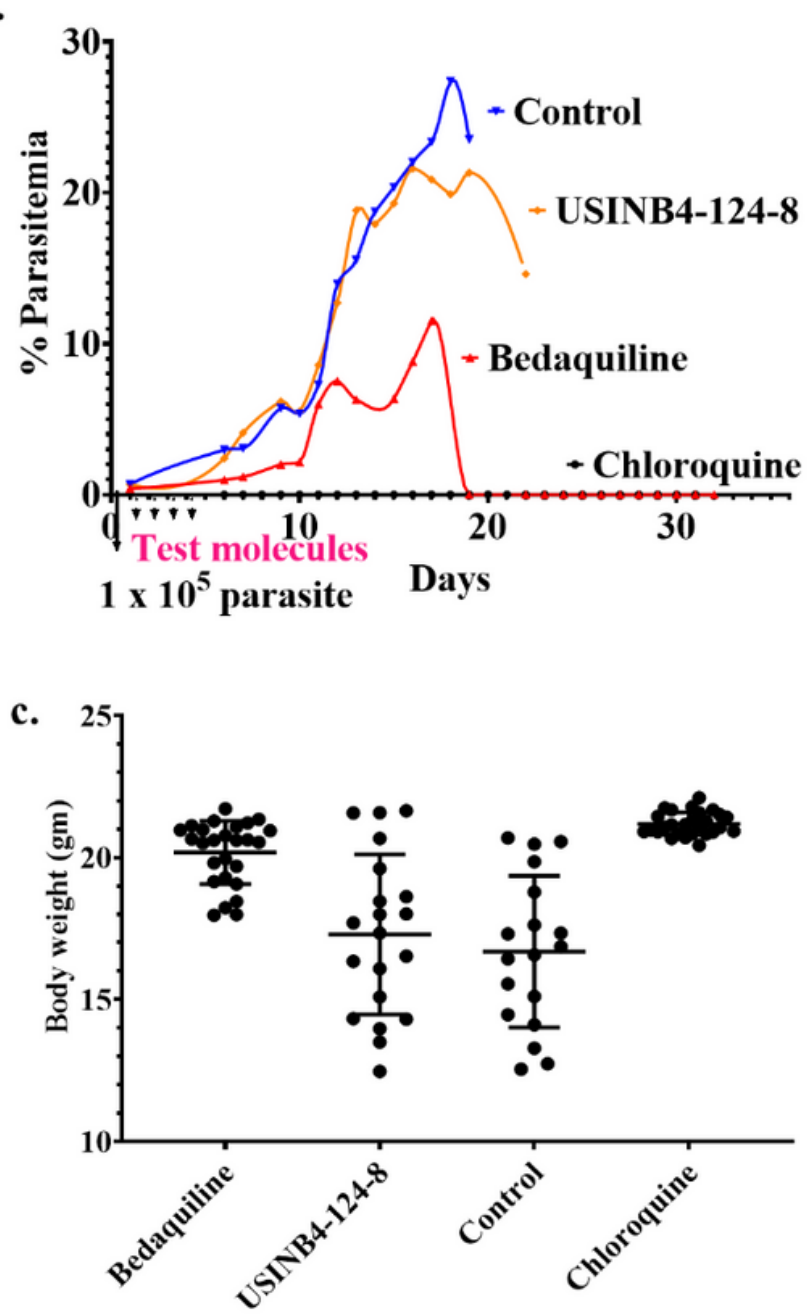
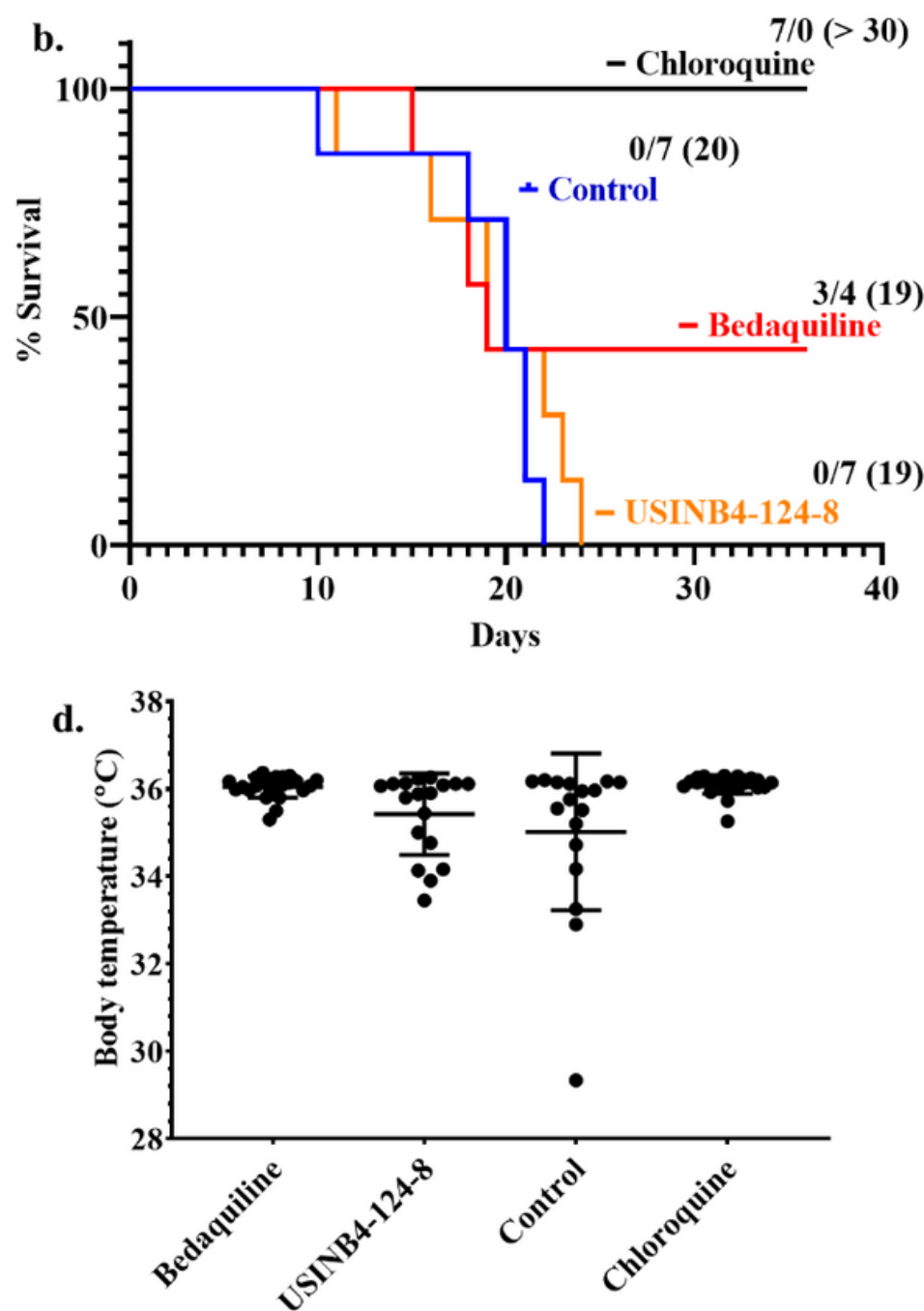

Figure 8

Rise in mean \% Parasitemia (a) and median survival time (b) with change in mean body weight (c) and temperature (d). Superscripts in black (B) indicate Alive/Dead mice with mean survival in days in parentheses Each dot in a group (C and D) represents a single day.

\section{Supplementary Files}

This is a list of supplementary files associated with this preprint. Click to download.

- Supplementaryfile1.docx

- Supplementryfile2.xlsx 